\title{
Study on Impact Characteristics of Multistage Double Crown Face Gear Pairs considering Ratio Switching under Variable Conditions
}

\author{
Xingbin Chen $\left(\mathbb{D},{ }^{1,2,3}\right.$ Xinhe Min, ${ }^{1,3}$ Peng Zhang, ${ }^{1,3}$ Nini Li, ${ }^{1,3}$ Zhihong Zhong, \\ and Yuansheng $\mathrm{Wu}^{1,3}$ \\ ${ }^{1}$ Guangzhou Mechanical Engineering Research Institute Co., Ltd., Guangzhou 510700, China \\ ${ }^{2}$ School of Mechanical and Automotive Engineering, South China University of Technology, Guangzhou 510641, China \\ ${ }^{3}$ CRAT Testing \& Certification Company Ltd., Guangzhou 510700, China \\ ${ }^{4}$ BOLUO Science, Technology, Industry and Information Bureau, BOLUO Investment Promotion Center, Huizhou, \\ Guangdong 516100, China \\ Correspondence should be addressed to Xingbin Chen; cxb19862003@163.com
}

Received 3 March 2020; Revised 22 May 2020; Accepted 20 July 2020; Published 5 August 2020

Academic Editor: Roberto Palma

Copyright ( 2020 Xingbin Chen et al. This is an open access article distributed under the Creative Commons Attribution License, which permits unrestricted use, distribution, and reproduction in any medium, provided the original work is properly cited.

\begin{abstract}
This paper presents a new transmission mechanism with multistage face gears as the core components for realizing variable speeds with differential meshing. To improve face gear transmission smoothness, suppress meshing resonance, reduce noise, and optimize power transmission performance during the gear shifting process, load distribution between meshing teeth during the transmission process and impact loads during various shifting stages must be determined. Herein, we present a gear impact model considering double crown gear meshing configuration, contact deformation, variable working conditions, and jump impact at meshing points. A single-stage face gear pair is considered as object that the impact characteristics are comparatively studied under four conditions: with/without load and constant/variable speed. The results were used to analyze transient characteristics of the crown gear under contact deformation or frequent shifting impact. Based on this, the impact characteristics of multistage face gear pairs between ratio switching were extendedly investigated under four input conditions: constant/variable torque or constant/variable speed. The results were used to determine the meshing force and impact force fluctuation characteristics of multistage face gear pairs while adapting to various loads and continuous acceleration/deceleration. The proposed model can be beneficial to evaluate the feasibility of multistage gear structures with crown configuration and to obtain boundary conditions for transmission systems.
\end{abstract}

\section{Introduction}

Multistage face gears need to adapt to the conditions of heavy load, high speed, and variable load, in order to improve the reliability of transmission system under the extreme conditions such as impact and slide during shifting process [1]. However, to analyze contact impact states of face gears, accurate models of real application conditions are built. During dynamic meshing, the transmission systems generate impact, vibration and noise due to large conditions fluctuating, elastoplastic deformation and sliding friction load in acceleration, deceleration, variable torque, and ratio shifting $[2,3]$. Therefore, it is of great significance to study the impact characteristics of face gear for the vibration noise reduction mechanism and dynamic design of transmission system.

For impact problem, scholars have mainly focused on the meshing behavior of single-stage gear caused by load elastoplastic deformation and installation error $[4,5]$. Fewer studies have assessed the transient impact of transmission system with speed ratio switching [6]. Wang systematically investigated the effect of transient squeezing on the performance of spiral bevel gears with and without real machined surface roughness, which was compared with the corresponding steady-state elastohydrodynamic lubrication (EHL) results. The results reveal that the transient squeezing 
action can significantly affect the film thickness distribution in each contact zone and along the meshing track line in spiral bevel gears and lead to dramatic growth in asperity contact area as well [7]. Tan proposed an electromechanical coupled dynamic model of wind turbine drivetrain. Considering the bearing clearances, the impacts occur in the planet bearing in the minimum load zone followed by significant stress variation; the planet position angle has a significant effect on the planet bearing impacts because of the asymmetry of load and structure of the planetary gear stage [8]. Xiang proposed an improved gear contact force model for dynamic analysis in helical gear transmission system. In this model, a new factor associated with hysteresis damping is developed for contact-impact state. For determining the selection strategy of these two damping factors, the fundamental contact mechanics of contact-impact event affected by supporting forces are analyzed [9]. Gui established a lumped parameter model for a typical planetary gear system with various types of errors. In the model, the influences of tooth faults on time-varying mesh stiffness and tooth impact force are derived analytically [10]. Mu presented an optimization design method for vibration control base on the meshing impact model to minimize the running vibration of spiral bevel gear. Firstly, based on the impact model of spiral bevel gears considering tooth deformation, the initial meshing position, meshing stiffness, and the meshing impact are studied. Secondly, the effects of load torque and rotation speed on meshing impact are analyzed [11]. Kimme presented a detailed simulation of the gear production process, providing crucial information about characteristic process properties and enabling investigations on the impact of manufacturing process on gear mesh acoustics. Microgeometry of the gear is of relevance for the vibration excitation in the tooth contact and significantly affected by the manufacturing process, especially the finishing operations [12]. Chung proposed a dynamic model for a spur gear transmission system that contains damping particles inside the holes on gear bodies, using two-way coupling with multibody dynamics and discrete element method. Numerical results show that vibration in the transmission is appreciably attenuated by the particle damping mechanism and the contact friction [13]. Ziegler presented a modally reduced elastic multibody model including contact that allows very precise simulations in reasonable time. To evaluate how appropriate these rigid body models are to simulate impact forces, a very detailed finite element model is used to simulate several impacts, and the results are compared to simulations with a rigid body model [14]. Tang introduced a nonlinear viscoelastic contact force model to establish the impact dynamic equations considering the meshing gear system as an impact-contact model. With the application of numerical integration, the bifurcation characteristics and energy dissipation are analyzed. Numeric results show that the system has complex dynamic behaviors [15].

To date, the studies of face gears have mainly focused on the geometric structure, meshing behavior, and kinematics characteristics. Face gear is thought to inherit the periodic and smooth meshing characteristics of involute gears, but less attention has been paid to the impact characteristics during meshing process $[16,17]$. For a crown face gear with point contact, impact impacts are easily caused by factors such as contact deformation and meshing point fluctuations due to design, machining errors, or changes conditions [18]. This paper studies the impact characteristics of single/ multistage face gear pairs by numerical calculations and multibody dynamics modeling methods under four conditions: no/variable load or constant/variable speed. A transient contact dynamic model is established for various conditions that can be used to determine dangerous points of contact or bending strength of face gears tooth surface by analyzing the impact force fluctuations rule during meshing processing. Finally, a model of impact load is derived for various transmission stages to assess changes rule in impact load or sliding friction during gear shifting process and determine the meshing strength limit of interstage loading. The results provide important references for the design and manufacture of novel multistage face gear transmission which accelerate toward practical engineering applications.

\section{Structural Model and Contact Relationship of Multistage Crown Face Gear Pair}

The multistage face gear pair consists of a series of singlestage face gears meshing with cylindrical gears. A face gear double crown constructed from a straight tooth surface was previously proposed to prevent interference by unsynchronized motion between various face gears within the same cylindrical gear, improve contact characteristics, and achieve stable transmission, which was verified by experiment $[19,20]$.

2.1. Structural Model of Multistage Face Gear Pair with Double Crown Configuration. Structure parameters of the model were selected according to the transmission system. Cylindrical gear: module (4 symmetrical arrangement) $m_{c}=2$, number of teeth $z_{c}=19$, pressure angle $\alpha=20^{\circ}$, addendum coefficient $h_{a}^{*}=1.0$, and tip clearance coefficient $c^{*}=0.25$. Face gear: module $m_{f}=3$, number of teeth (per level must be in multiples of 4) $z_{f a}=56, z_{f b}=68, z_{f c}=80$, pressure angle $\alpha=20^{\circ}$, addendum coefficient $h_{a}^{*}=1.0$, and tip clearance coefficient $c^{*}=0.25$. The components' structure and assembly structure are shown in Figure 1.

Physical prototypes of each single-stage face gear, as shown in Figure 2, were milled by a three-axis computer numerical control (CNC) machine tool.

2.2. Definition of Contact and Impact Relationship for Multistage Crown Face Gear Pair. Contact impact of face gear is a nonlinear process, which includes normal meshing contact and transient impacts due to factors such as machining error, variable speed, backlash, and deformation. Therefore, the contact-impact relationship must include deformation due to gear teeth shearing, bending, meshing point load concentration, and tooth body deflection [21]. During the meshing process of the multistage face gear, the load and speed are transferred between the working face gear and 


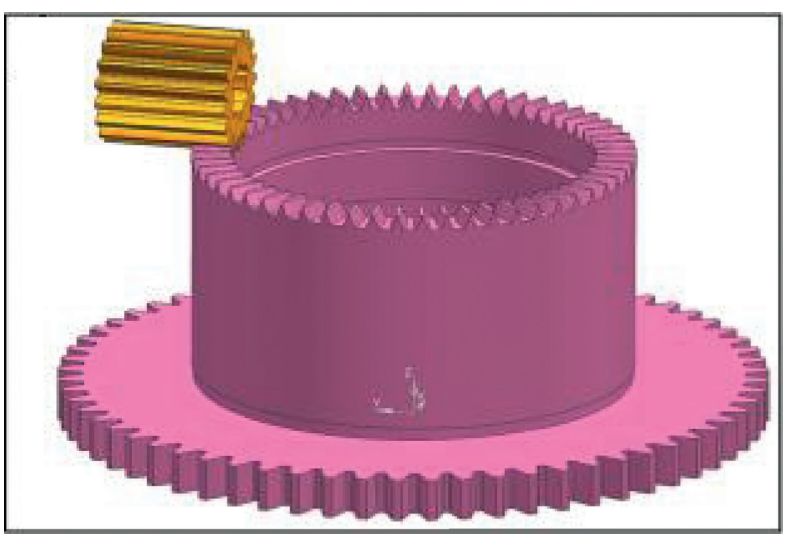

(a)

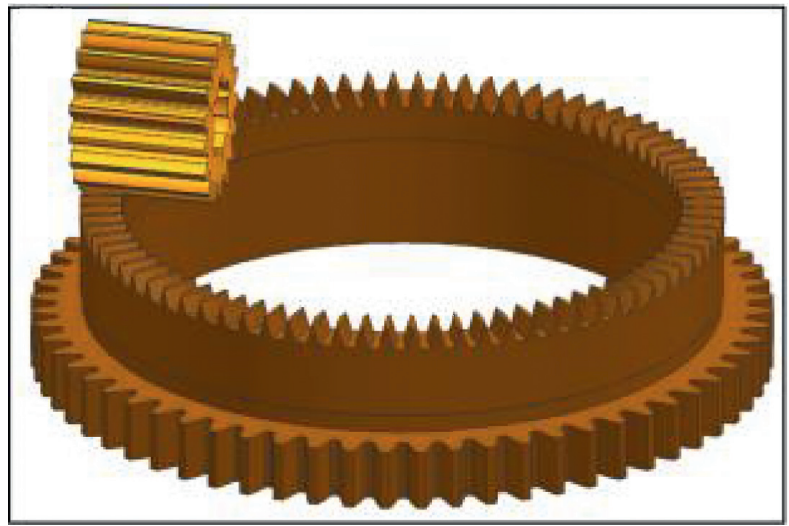

(c)

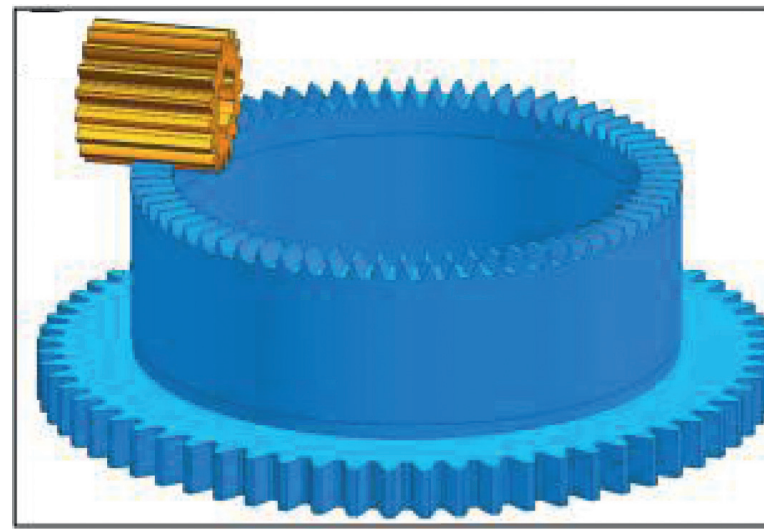

(b)

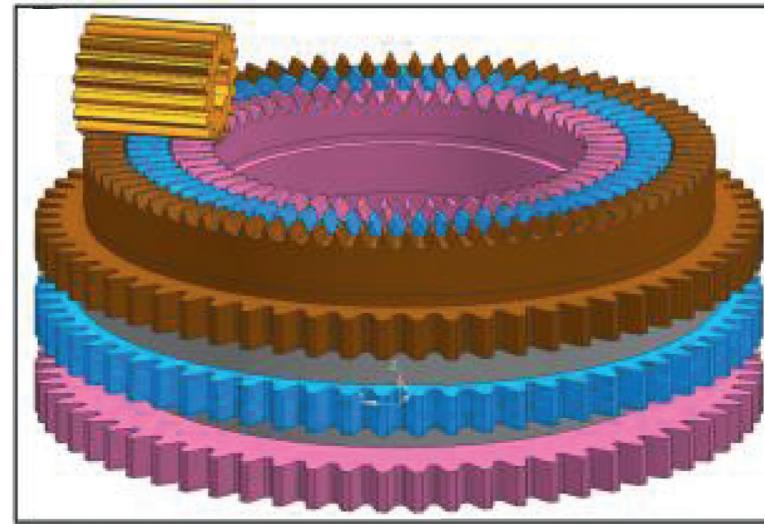

(d)

FIGURE 1: Model of multistage face gear pair with double crown configuration. (a) Level 1 face gear entity. (b) Level 2 face gear entity. (c) Level 3 face gear entity. (d) Multistage face gears entity.

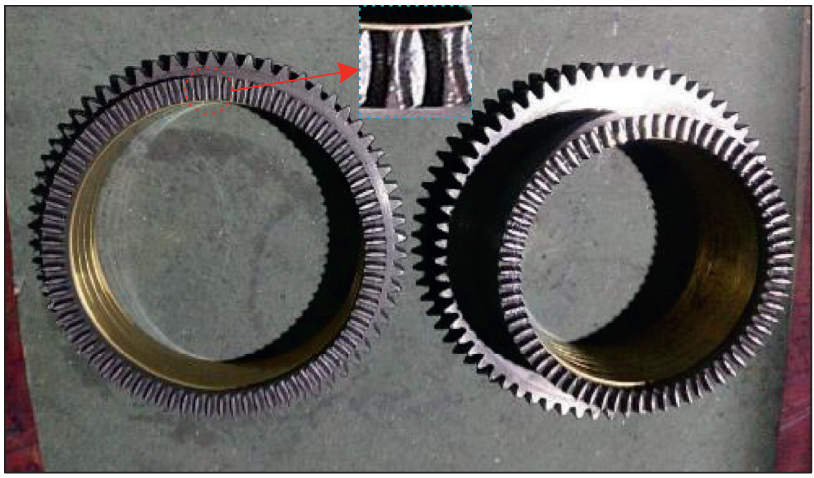

(a)

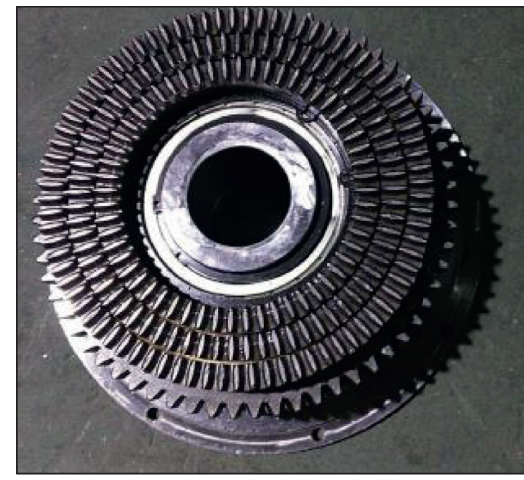

(b)

FIgURe 2: Physical prototype of multistage face gears. (a) Single-stage face gear. (b) Assembled multistage face gears.

original free-running face gear through cylindrical gears in order to accommodate variable speeds. However, when the gear exits the upper and enters the next meshing stages, the actual position of the meshing point will not be on the same stage gear meshing line but will jump directly to the nextstage meshing line. Thus, unsynchronized meshing occurs causing variable speeds between stages of the transmission process which results in impact excitation between meshing stages.
The gear meshing force is assumed to be the impact force between two cylinders with different curvatures in contact. The contact relationship can be defined according to the Hertz elastic contact theory [22], as shown in Figure 3. When two objects come into contact with each other, the impact force is composed of two parts: an elastic force due to mutual penetration between two objects and a sudden change in momentum caused by the damping force as a result of changes in relative speed or load, as shown in Figure 4. 


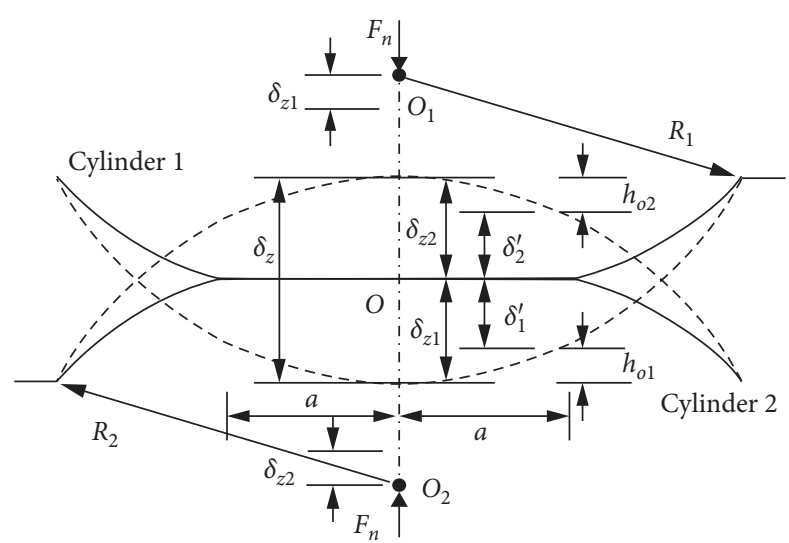

Figure 3: Hertz elastic contact relationship.

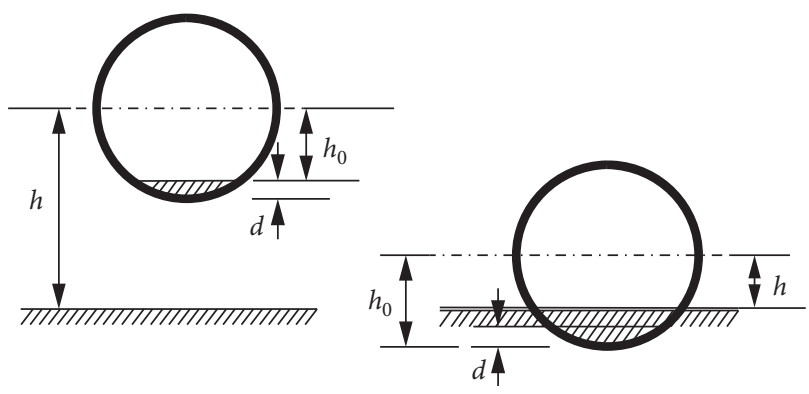

FIgURE 4: Impact contact process.

For impact between two rotating objects, as shown in Figures 3-4, $a$ is the effective length of the contact area, $R$ is the relative radius of curvature, $h$ is the contact gap, and $R_{1}$ and $R_{2}$ are the radii of two objects affected by normal force $F_{n}$. According to the Hertz theory [23], the geometric representation of the contact area is

$$
\left\{\begin{array}{l}
h=\frac{x^{2}}{2 R}+\frac{y^{2}}{2 R}, \\
\frac{1}{R}=\frac{1}{R_{1}}+\frac{1}{R_{2}} .
\end{array}\right.
$$

During impact compression process, points $\mathrm{O}_{1}$ and $\mathrm{O}_{2}$, respectively, move $\delta_{z 1}$ and $\delta_{z 2}$ to point $O$ which parallel with $z$-axis, and the magnitude of deformation on both sides is $\delta_{1}^{\prime}$ and $\delta_{2}^{\prime}$; then the relationship of impact deformation can be expressed as

$$
\delta_{1}^{\prime}+\delta_{2}^{\prime}=\delta_{z 1}+\delta_{z 2}-h_{01}-h_{02}=\delta-\frac{\left(x^{2}+y^{2}\right)}{2 R}=\delta-\frac{r^{2}}{2 R} .
$$

Here, $\delta=\delta_{z 1}+\delta_{z 2}$ is the total deformation of contact body. $r^{2}=x^{2}+y^{2}$ is the transient radius of mass center and contact point.

\section{Contact Analysis of Crown Face Gear Pair Meshing}

The double crown configuration for face gear can realize point contact transmission. Under loading, the tooth surface of face gear will have a certain amount of elastic deformation, and the semiaxis size of the transient contact ellipse can be calculated at each contact point. The series of contact ellipses constitute the contact area of face gear tooth surface [24]. Assuming that the curvature radii at the contact points between gear teeth of cylindrical and face gears during the transmission process are $k_{1}^{c}, k_{2}^{c}$, and $k_{1}^{f}, k_{2}^{f}$, respectively. Then, the length of two semiaxes in the meshing area can be calculated according to the principal curvature of the contact point and the elastic coefficient of two gears [25]:

$$
\left\{\begin{array}{l}
a^{\prime}=u \cdot \sqrt{\frac{1.5 F}{k_{1}^{c}+k_{2}^{c}+k_{1}^{f}+k_{2}^{c}}\left(\frac{1-\mu_{c}^{2}}{E_{c}}+\frac{1-\mu_{f}^{2}}{E_{f}}\right)} \\
b^{\prime}=v \cdot \sqrt[3]{\frac{1.5 F}{k_{1}^{c}+k_{2}^{c}+k_{1}^{f}+k_{2}^{c}}\left(\frac{1-\mu_{c}^{2}}{E_{c}}+\frac{1-\mu_{f}^{2}}{E_{f}}\right)}
\end{array}\right.
$$

Here, $\mu_{c}$ and $\mu_{f}$ are the Poisson ratio of two gears' materials. $E_{c}$ and $E_{f}$ are the elastic moduli of two materials. $u$ and $v$ are the elliptic integral functions of tooth surface contact trajectory.

3.1. Meshing Impact Speed Assumption. During the meshing process of a single-stage face gear (i.e., constant ratio transmission), the meshing impact can be assumed to be center-to-center contact impact of two orthogonal angular moving mass bodies with different radius [26]. According to the meshing principle, the absolute speeds of two gears in the tangential direction of any contact point on the teeth surfaces are different, which results in relative sliding between two tooth surfaces. The speed along the meshing line is the meshing impact speed, as shown in Figure 5.

The relative sliding speed $v_{12}$ can be expressed as

$$
\begin{aligned}
v_{12} & =v_{2}-v_{1}=\sqrt{v_{2 t}^{2}+v_{2 n}^{2}}-\sqrt{v_{1 t}^{2}+v_{1 n}^{2}} \\
& =\sqrt{\left(w_{f} r_{2}\right)^{2}+\left(w_{c} r_{1}\right)^{2}}-\sqrt{\left(w_{c} r_{1}\right)^{2}+\left(w_{c} r_{1} \cos \alpha\right)^{2}}, \\
& =w_{c}\left(\sqrt{\left(\frac{1}{q_{f s i}^{2}}\right)\left(r_{f}^{2}+s^{2}\right)\left(r_{c}^{2}+s^{2}\right)}-\sqrt{\left(r_{c}^{2}+s^{2}\right)\left(1+\cos ^{2} \alpha\right)}\right) .
\end{aligned}
$$

Here, $\omega_{c}$ and $\omega_{f}$ are the angular speeds of cylindrical gear and face gears; $r_{c}$ and $r_{f}$ are the reference circle radii of two gears; $s=r_{c} \tan \alpha$ is the distance between any contact point and node on the mesh line; and $q_{f s i}$ is the transmission ratio.

Multistage face gears produce impact excitations between stages in the meshing process due to variable speed. Changes in load and speed can lead to error and deformation in the gear teeth meshing surface because of the speed changing mechanism. Therefore, the meshing point will deviate from the theoretical meshing line, and both the speed and torque of the gear will change abruptly with the transmission ratio, as follows: 


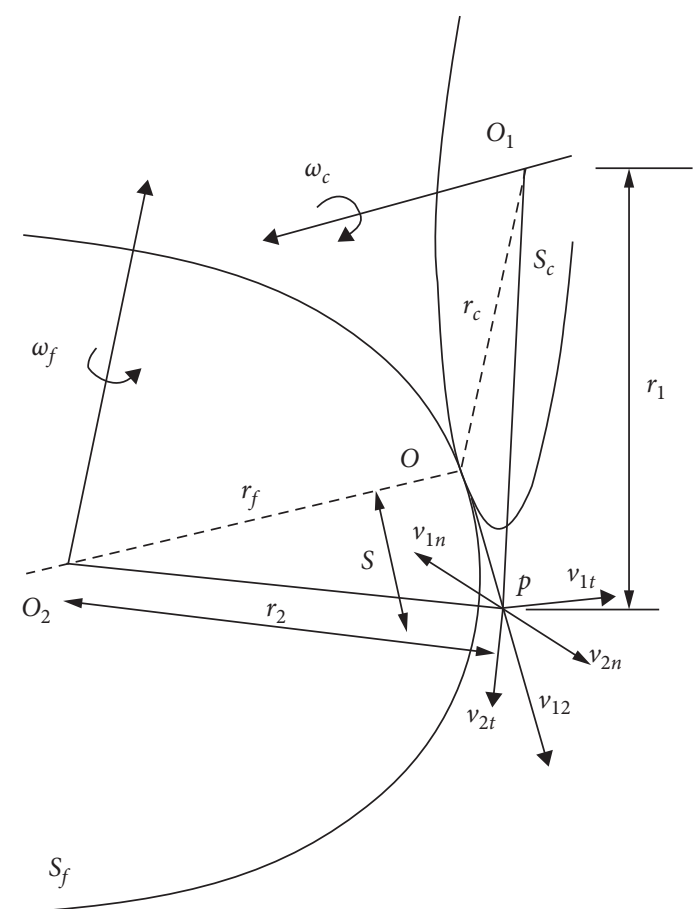

FIGURE 5: Meshing impact speed assumption.

$$
v_{s}=\omega_{c} r_{c}\left(1+\frac{1}{q_{c f i}}\right)\left[1-\frac{\cos \left(\alpha_{c f}^{\prime}+\gamma_{c f}^{\prime}\right)}{\cos \alpha}\right] \text {. }
$$

Here, $v_{s}$ is the meshing impact speed; $\omega_{c}$ is the angular speed of cylindrical gear; $q_{c f i}$ is the transmission ratio of the cylindrical and working face gear pair, which changes with speed stage shifting; $\alpha$ is the reference circle pressure angle from the gear design; $\alpha_{c f}^{\prime}=\arctan \left(s / r_{c}\right)$ is the pressure angle of actual meshing point; and $\gamma_{c f}^{\prime}=\arccos$ $\left(r_{c}^{2} / \sqrt{r_{c}^{2}+r_{f}^{2}} \sqrt{r_{c}^{2}+s^{2}}\right)$ is the angle between the connecting line from meshing point to the cylindrical gear center and the center line of two gears.

3.2. Contact Meshing Force Analysis of Face Gear. When the tooth surfaces of a gear pair collide instantaneously, a continuous fit cannot be maintained due to the load. Therefore, the driven gear instantly accelerates and separates from the driving wheel and thus reciprocates. During this process, a resultant impact force is transmitted by the gears via mutual contact between the gear teeth. According to the Hertz contact mechanics model, as shown in Figure 6, the meshing force direction is difficult to completely match the theoretical mesh line owing to transmission error and structural deformation during the elastic action of gears meshing. Considering material damping, the generalized Hertz gear meshing force can be expressed as $[27,28]$

$$
F_{m}=K_{c f} \delta_{c f}^{\xi}+D_{c f}(x) \dot{\delta}_{c f}^{\xi} .
$$

Here, $F_{m}$ is the gear meshing force; $K_{c f}$ is the Hertz contact stiffness; $\delta_{c f}^{N}$ is the relative deformation of two mass bodies in the normal direction of contact tooth surface; $\dot{\delta}_{c f}^{N}$ is the relative contact speed; $D_{c f}(x)=\lambda x^{\xi}$ is the damping coefficient; $\lambda=(3 / 2) a K_{c f}$ is the hysteresis damping coefficient; $a$ is the power exponent of the nonlinear damping force, usually $a=1.5 ; x=\left(9 T^{2} / 16 R E^{* 2}\right)^{1 / 3}$ is the distance between contact points of two rotating bodies, and $T$ is the torque applied to the object; and $\xi$ is the impact index.

In general, contact impact is divided into normal contact, tangential contact, and mixed contact (depending on the normal force):

$$
F_{m}=F_{n}+F_{t} \text {. }
$$

Here, $F_{n}$ is the normal contact force; $F_{t}$ is the tangential contact force.

If the deformations of gear teeth occur during the meshing process, an equivalent spring damping model can be used to solve the gear normal contact force:

$$
F_{n}=K_{c f} \delta_{c f}^{\xi}+C(\delta) \delta_{c f}^{\xi} .
$$

Here, $C(\delta)$ is a polynomial representing contact damping.

Considering sliding friction between gears, the Coulomb friction model can be used to represent the tangential contact force, as follows:

$$
F_{t}=-\mu F_{n} \operatorname{sgn}\left(v_{12}\right) \text {. }
$$

Here, $\mu$ is the friction coefficient; $\operatorname{sgn}\left(v_{12}\right)$ is a step function of meshing relative speed:

$$
\begin{cases}\operatorname{sgn}\left(v_{12}\right)=-1, & v_{12}<0, \\ \operatorname{sgn}\left(v_{12}\right)=0, & v_{12}=0, \\ \operatorname{sgn}\left(v_{12}\right)=1, & v_{12}>0 .\end{cases}
$$

3.3. Contact Analysis of Face Gear Impact Force. An impact force generated by two objects, such as gear meshing force, can be simplified as an impact problem between two cylinders with variable curvature. According to the IMPACT function of the multibody dynamics software ADAMS, when two objects come to contact with each other, the impact force is composed of two parts: an elastic force due to mutual penetration between two objects and a momentum mutagenicity due to the damping force generated by relative speed [29]. Therefore, the contact impact force is defined as [30]

$$
F_{\text {imp }}= \begin{cases}K_{c f}\left(h-h_{0}\right)^{\xi}-C_{\max }(d h / d t) \times \operatorname{step}\left(h, h_{0}-d, 1, h_{0}, 0\right), & h<h_{0}, \\ 0, & h \geq h_{0} .\end{cases}
$$




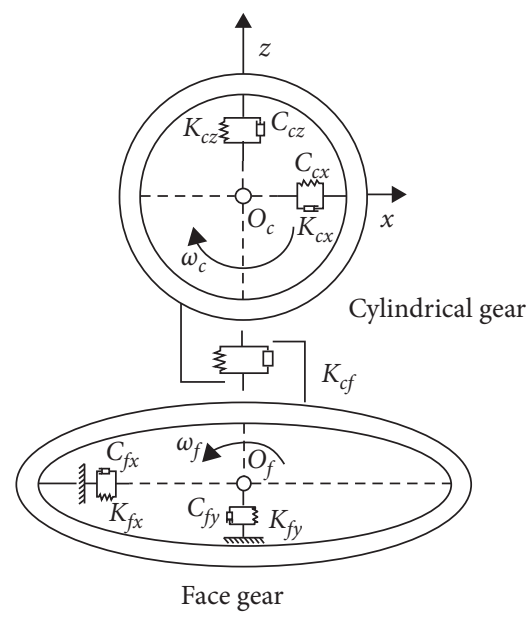

Figure 6: Simplified model of face gear contact dynamics.

Here, $h_{0}$ is the initial distance before impact, $\mathrm{mm} ; h$ is the actual distance during impact, $\mathrm{mm}, s=h-h_{0}$; $\xi$ is the impact index, $\mathrm{mm} ; C_{\max }$ is the max contact damping polynomial, N-s/mm; and $d$ is the penetration depth of impact, $\mathrm{mm}$.

3.3.1. Stiffness Coefficient. According to the Hertz contact theory, the contact stiffness coefficient is [31]

$$
K_{c f}=\frac{4}{3} E^{*} R^{0.5} \text {. }
$$

Here, $\quad E^{*}=\left(E_{c} E_{f} / E_{c}\left(1-\mu_{f}^{2}\right)+E_{f}\left(1-\mu_{c}^{2}\right)\right)$ is the comprehensive elastic modulus of the meshing gears; $E_{c}, E_{f}$ are the elastic moduli of cylindrical gear and face gear, respectively; $\mu_{c}, \mu_{f}$ are Poisson's ratios of two gears; $(1 / R)=\left(1 / R_{1}\right)+\left(1 / R_{2}\right), R_{1}, R_{2}$ are the effective radii of two gears (if impact occurs between teeth, the equivalent radius of gear meshing contact points can be approximately replaced by the reference circle radius).

3.3.2. Impact Index. The impact index reflects the nonlinearity degree of material. Generally, $\xi=1.5$ for metal materials and $\xi=2$ for rubber materials.

3.3.3. Maximum Contact Damping Polynomial. A nonlinear hysteretic damping model is adopted to characterize the impact energy loss [32]:

$$
C_{\max }= \begin{cases}\frac{3 K_{c f}\left(1-e^{2}\right)}{4 v_{k}} \delta^{a}, & e \approx 1, \\ \frac{3 K_{c f}\left(1-e^{2}\right) \exp (2(1-e))}{4 v_{k}} \delta^{a}, & 0<e<1 .\end{cases}
$$

Here, $e$ is the impact recovery coefficient; $\delta$ is relative deformation; and $v_{k}$ is the meshing impact speed $\left(v_{k}=v_{12}\right.$ for single-stage face gear, $v_{k}=v_{s}$ for multistage face gears).
3.3.4. Impact Recovery Coefficient. The impact recovery coefficient represents kinetic energy loss during impact process, which can be used to analyze the dynamic characteristics of gear transmission system under contact deformation. During the two stages of compression and elastic recovery in contact impact process, the elastic body includes not only elastic deformation, but also elastic-plastic deformation and finite plastic deformation. According to Johnson's model [33], the impact process can be decomposed into a fully elastic part and a plastic part, as follows:

$$
e= \begin{cases}1, & (0<j \leq 1), \\ 1-0.035 \ln (j) \times j^{0.1645}, & \left(1<j \leq j_{l y}\right) .\end{cases}
$$

Here, $j$ is the yield ratio of impact, $j=\left(v_{k} / v_{y}\right)$, $j_{l y}=\left(v_{l} / v_{y}\right)$, and $v_{l}$ is the maximum speed of shallow indentation theory, generally $100 \mathrm{~m} / \mathrm{s}$.

The impact yield speed $v_{y}$ is expressed as

$$
v_{y}=\left(\frac{26 Y_{f}^{5}}{\rho_{c} E^{* 4}}\right)^{1 / 2} \text {. }
$$

Here, $Y_{f}$ is the yield strength of face gear and $\rho_{c}$ is the density of cylindrical gear.

3.3.5. Relative Contact Deformation. The relative deformation of maximum damping is defined as deformation of elastic-plastic contact impact [34]:

$$
\delta=\left(\frac{5 m_{k} v_{k}^{2}}{4 K_{c f}}\right)^{2 / 5} .
$$

Here, $m_{k}=\left(m_{c} m_{f} / m_{c}+m_{f}\right)$ is the comprehensive mass of two elastomers and $m_{c}$ and $m_{f}$ are the mass of the cylindrical gear and face gear, respectively.

3.3.6. Impact Penetration Depth. Just before two objects come into contact, the damping component is zero; then, damping reaches a maximum when two objects interpenetrate to a defined depth $d[35]$ :

$$
d=\left(\frac{9 F_{n}^{2}}{16 R E^{* 2}}\right)^{1 / 3} \text {. }
$$

\section{Dynamics Analysis of Single-Stage Crown Face Gear Pair without Speed Ratio Switching Influence}

According to the universal gear design manual and considering variable speed impact loads [36], 20CrMnTi was selected as the material for both cylindrical gears and face gears; the densities are $\rho_{c}=\rho_{f}=7.86 e+3 \mathrm{~kg} / \mathrm{m}^{3}$; the Poisson ratios are $\mu_{c}=\mu_{f}=0.289$; and the elastic moduli are $E_{c}=E_{f}=2.12 e+11 \mathrm{~Pa}$. A dynamic analysis model was established by ADAMS, as shown in Figure 7.

4.1. Impact Characteristics Analysis under Variable Conditions with No Loading. The force index was 1.5, the damping 


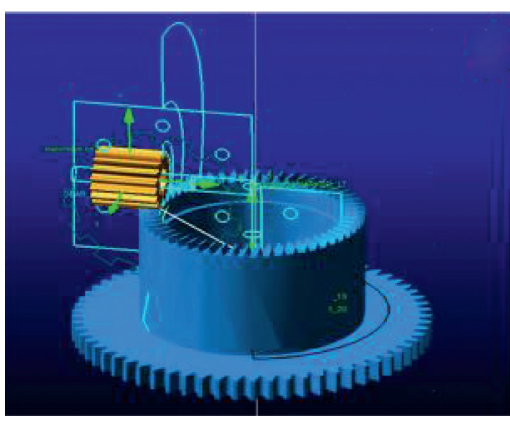

(a)

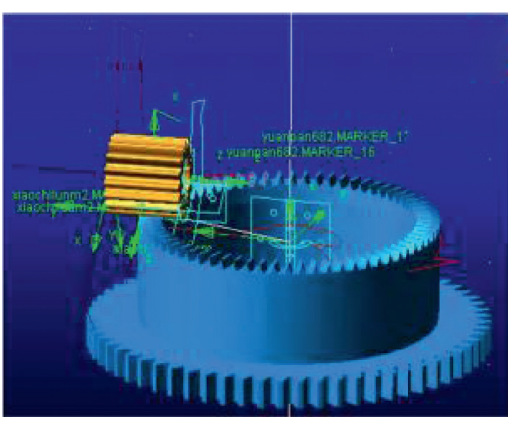

(b)

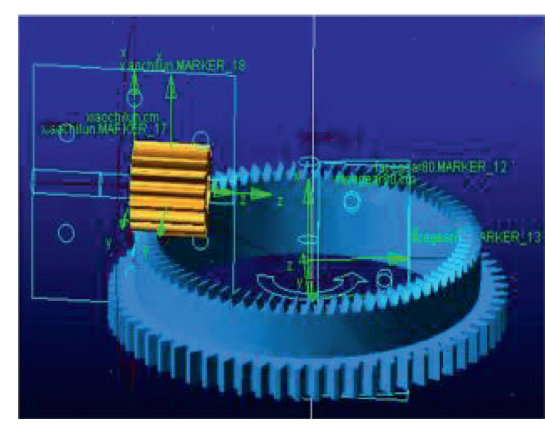

(c)

Figure 7: Dynamic model of single-stage face gear in ADAMS.

coefficient was 10.0, and the penetration depth was 0.1 . Considering the friction during the impact, two gears were greased; then the dynamic friction coefficient was set as 0.02 , the static friction coefficient was 0.05 , the time was set to $5.0 \mathrm{~s}$, and the step size is 500. Input speeds were 100,300, and $1000 \mathrm{r} / \mathrm{min}$ (corresponding to $600 \mathrm{~d}, 1800 \mathrm{~d}$, and $6000 \mathrm{~d}$ in the ADAMS system), respectively. The simulated impact elastic displacement, impact speed, impact force, and impact potential energy of first-stage face gear pair are presented in Figures 8-11.

The impact elastic displacements, impact speeds, impact forces, and impact potential energies of first-stage, secondstage, and third-stage face gear pairs are shown in Tables 1-3, respectively. The boundary conditions and model parameters remained the same in each stage.

In the gear transmission process, due to the vibration and impact caused by meshing-in-out, the impact characteristics such as impact displacement, impact speed, impact force, and impact potential energy are periodic within a certain range. Under the condition with no loading, as the input speed increases, the fluctuation period of the impact displacement becomes shorter, the amplitude does not change, the average is not much different, but there is a significant modulation law. The fluctuation period of the impact speed becomes shorter, the amplitude becomes larger, and the average increases. The fluctuation period of the impact force becomes shorter, the amplitude becomes larger, and the average value increases significantly. In particular, due to the gear backlash and rotational motion inertia, the dynamic impact force reaches a large value even under condition with no loading. The fluctuation period of the impact potential energy becomes shorter, the amplitude remains unchanged but with a little downward deviation, which increases sharply during the meshing contact process, and the overall average is not much different.

The second-stage, third-stage face gears and first-stage face gear constitute of a multistage transmission structure in the rings form. Similarly, in the transmission process, the input speed period and frequency are approximately the same, so the impact characteristics periods are also approaching. However, due to the different teeth number in the multistage gears, the contact positions of impacting with the cylindrical gear are not the same. Compared with the first-stage face gear, the impact forces of the second and third stages increase significantly, and the impact potential energies also increase.

\subsection{Impact Characteristics Analysis under Constant Speed and} Variable Load. The force index was set to 1.5, the damping coefficient was 10.0, the penetration depth was 0.1 , the dynamic friction coefficient was 0.02 , the static friction coefficient was 0.05 , the input speed was $300 \mathrm{r} / \mathrm{min}$, and the time was set to $5.0 \mathrm{~s}$ with a step size of 500 . Input load torques were $50,200,500$, and $1000 \mathrm{~N} \mathrm{~mm}$. Impact elastic displacements, impact speeds, impact forces, and impact potential energies of second-stage face gear pair are presented in Figures 12-15.

The impact elastic displacement, impact speed, impact force, and impact potential energy of the second-stage face gear pair under variable load are shown in Table 4.

Under variable input speeds, no significant changes in the impact elastic displacement were observed for all stages' gears that due to the material and surface processing were roughly the same. Similarly, elastic displacement did not significantly change under variable load. This suggested that the material stiffness used in gears can adapt to frequent working conditions and changing load. As the input speed increased, the impact speed also increased, but as the load increased, only small fluctuations in impact speed were produced with a certain periodic characteristic. Under the condition with no loading, the time between gear tooth meshing and engaging-out is decreased as the input speed increased, but the impact force increased. Load changing also affected the average impact force and fluctuation amplitude. As the load increased, the relative impact speeds of gears increased, the meshing-in-out time was shortened again, and the accumulated relative impact force exhibited a strong nonlinear trend. Increasing the input speed and load would both cause the impact elastic potential energy to increase.

To better adapt to frequent changes in speed and loading, the crown tooth surface structure of each single-stage face gear should be optimized by reasonable gear processing method and technologies to meet variable speed boundary conditions and load limit of all stages' face gears. 


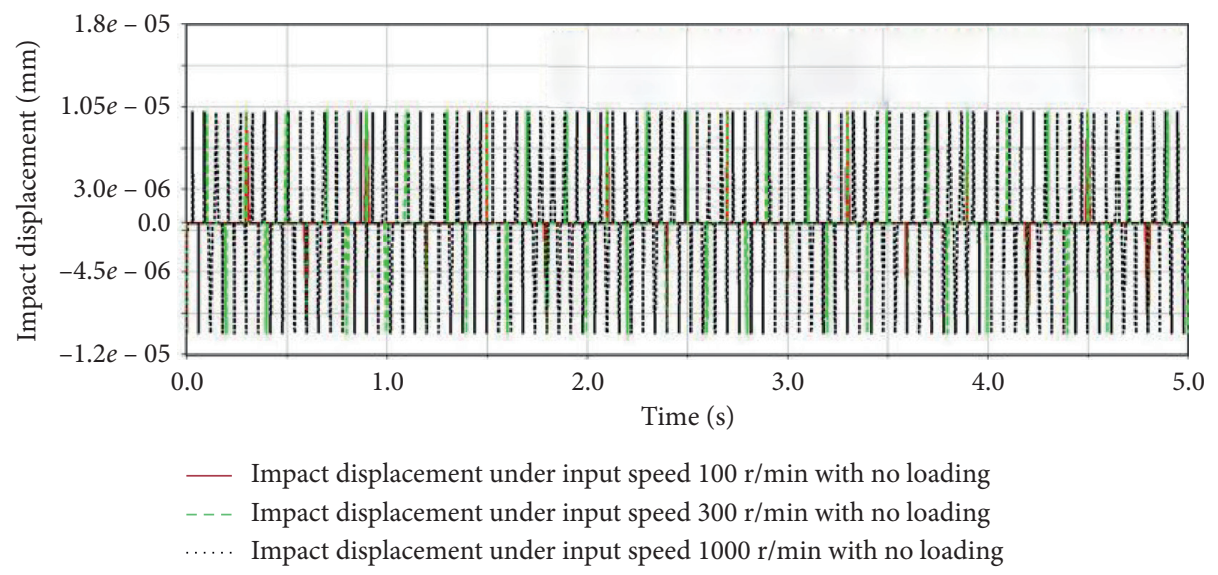

Figure 8: Impact elastic displacement of first-stage face gear pair with no loading.

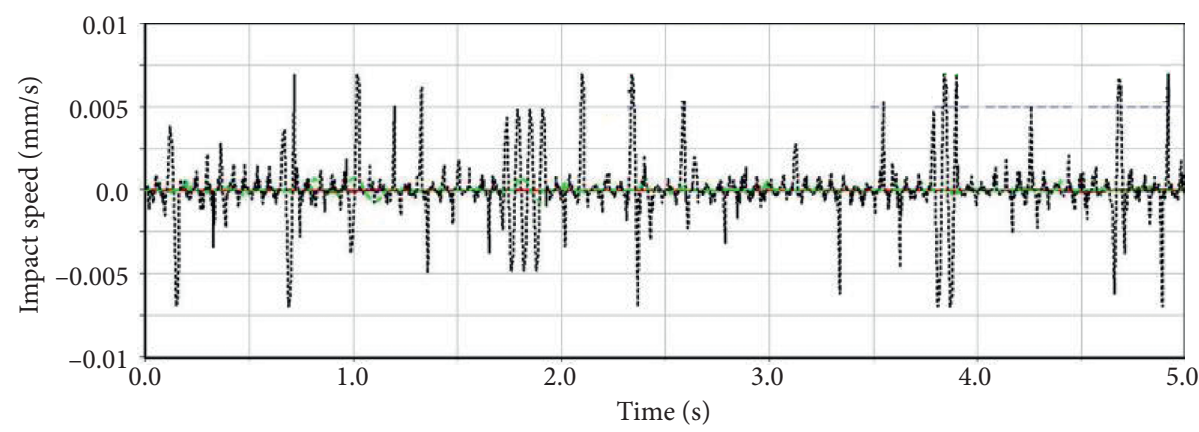

_ Impact speed under input speed $100 \mathrm{r} / \mathrm{min}$ with no loading

- - - Impact speed under input speed $300 \mathrm{r} / \mathrm{min}$ with no loading

..... Impact speed under input speed $1000 \mathrm{r} / \mathrm{min}$ with no loading

Figure 9: Impact speed of first-stage face gear pair with no loading.

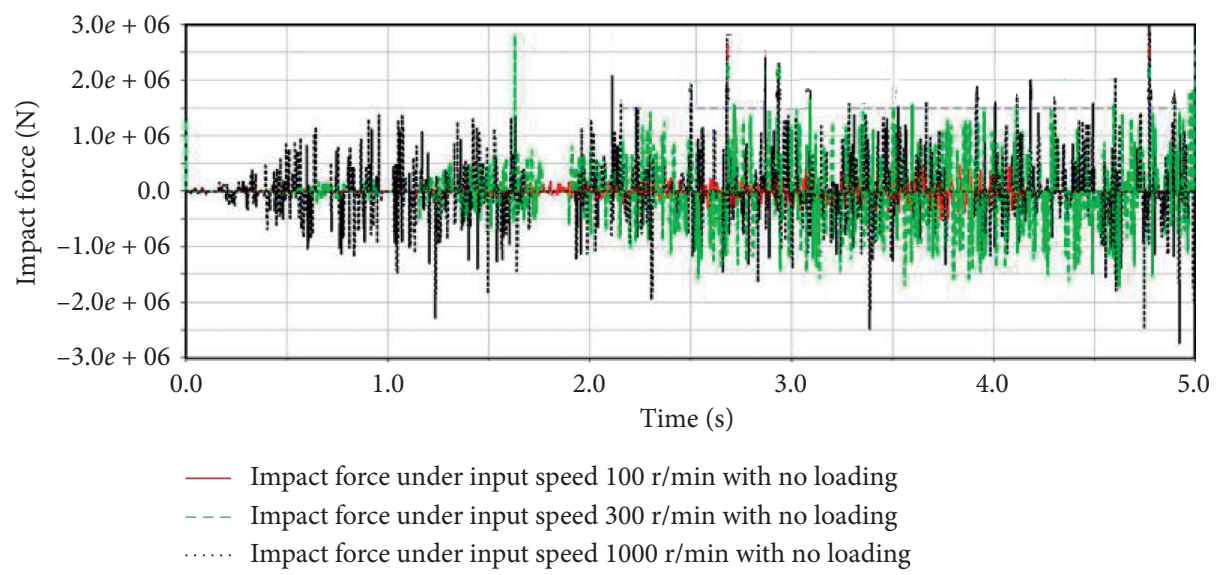

Figure 10: Impact force of first-stage face gear pair with no loading.

\section{Dynamic Analysis of Multistage Crown Face Gear Pair considering Speed Ratio Switching Influence}

The multistage crown face gear pair dynamic model is established in ADAMS, as shown in Figure 16, and
20CrMnTi was selected again as the cylindrical gear and face gear material.

Impact characteristics of the multistage face gear pair under speed ratio switching conditions can be defined as piecewise dynamics solutions of a multicontact system. To simulate the speed ratio switching relationship, the 


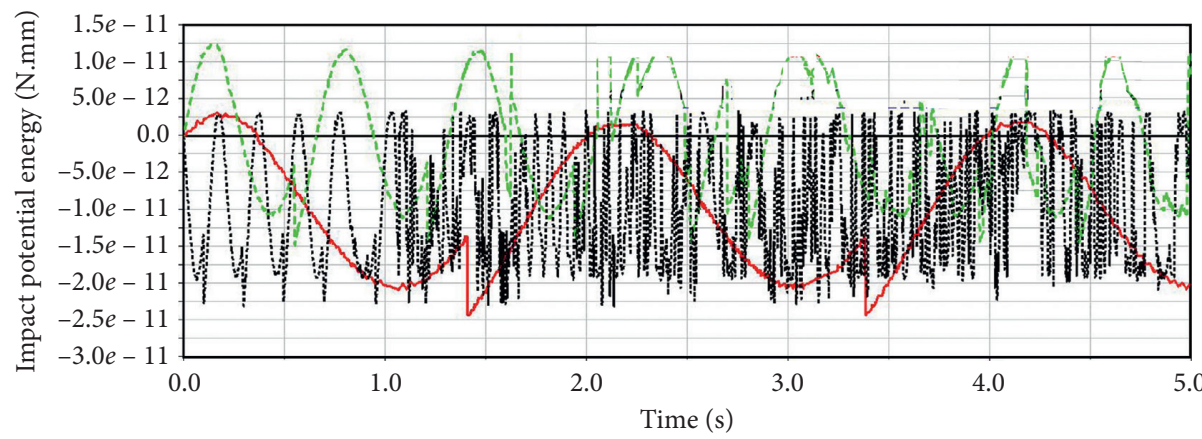

_ Impact potential energy under input speed $100 \mathrm{r} / \mathrm{min}$ with no loading Impact potential energy under input speed $300 \mathrm{r} / \mathrm{min}$ with no loading Impact potential energy under input speed $1000 \mathrm{r} / \mathrm{min}$ with no loading

FIGURE 11: Impact potential energy of first-stage face gear pair with no loading.

TABLE 1: Impact characteristics of first-stage face gear pair without load.

\begin{tabular}{|c|c|c|c|c|}
\hline \multirow{2}{*}{ Category } & \multirow{2}{*}{ Value } & \multicolumn{3}{|c|}{ Input speeds with no loading } \\
\hline & & $100 \mathrm{r} / \mathrm{min}$ & $300 \mathrm{r} / \mathrm{min}$ & $1000 \mathrm{r} / \mathrm{min}$ \\
\hline \multirow{3}{*}{ Elastic displacement (mm) } & Average & $-8.0199 e-9$ & $-6.2775 e-9$ & $-6.5348 e-9$ \\
\hline & Maximum & $1.0025 e-5$ & $1.0025 e-5$ & $1.0025 e-5$ \\
\hline & Minimum & $-1.0025 e-5$ & $-1.0025 e-5$ & $-1.0025 e-5$ \\
\hline \multirow{3}{*}{ Impact speed $(\mathrm{mm} / \mathrm{s})$} & Average & $2.1584 e-9$ & $9.9828 e-14$ & $3.0602 e-12$ \\
\hline & Maximum & $8.7977 e-11$ & $2.7733 e-10$ & $1.08 e-9$ \\
\hline & Minimum & $-1.7088 e-10$ & $-5.2114 e-10$ & $-7.494 e-10$ \\
\hline \multirow{3}{*}{ Impact force $(\mathrm{N})$} & Average & 3256.1729 & 9866.4246 & -13394.779 \\
\hline & Maximum & $5.5148 e+5$ & $1.706 e+6$ & $2.7373 e+6$ \\
\hline & Minimum & $4.7126 e+5$ & $-2.8154 e+6$ & $-2.9636 e+6$ \\
\hline \multirow{3}{*}{ Potential energy (N. mm) } & Average & $-1.0159 e-11$ & $-4.2425 e-13$ & $-9.8202 e-12$ \\
\hline & Maximum & $3.0774 e-12$ & $1.2347 e-11$ & $3.4151 e-12$ \\
\hline & Minimum & $-2.4337 e-11$ & $-1.4861 e-11$ & $-2.3118 e-11$ \\
\hline
\end{tabular}

TABLE 2: Impact characteristics of second-stage face gear pair without load.

\begin{tabular}{|c|c|c|c|c|}
\hline \multirow{2}{*}{ Category } & \multirow{2}{*}{ Value } & \multicolumn{3}{|c|}{ Input speeds with no loading } \\
\hline & & $100 \mathrm{r} / \mathrm{min}$ & $300 \mathrm{r} / \mathrm{min}$ & $1000 \mathrm{r} / \mathrm{min}$ \\
\hline \multirow{3}{*}{ Elastic displacement $(\mathrm{mm})$} & Average & $-1.7049 e-8$ & $-7.0152 e-9$ & $-1.159 e-8$ \\
\hline & Maximum & $1.0025 e-5$ & $1.0025 e-5$ & $1.0026 e-5$ \\
\hline & Minimum & $-1.0025 e-5$ & $-1.0025 e-5$ & $-1.0026 e-5$ \\
\hline \multirow{3}{*}{ Impact speed $(\mathrm{mm} / \mathrm{s})$} & Average & $6.4462 e-7$ & $2.396 e-6$ & $4.3966 e-6$ \\
\hline & Maximum & $7.8611 e-5$ & $7.062 e-4$ & 0.0074 \\
\hline & Minimum & $-7.8611 e-5$ & $-7.062 e-4$ & -0.0074 \\
\hline \multirow{3}{*}{ Impact force $(\mathrm{N})$} & Average & -1562.3735 & -1405.1084 & -5081.029 \\
\hline & Maximum & 12697.6068 & $1.3269 e+6$ & $4.3211 e+6$ \\
\hline & Minimum & $-8.8042 e+5$ & $-1.7125 e+6$ & $\mathrm{v} 3.178 e+6$ \\
\hline \multirow{3}{*}{ Potential energy (N. mm) } & Average & $3.8642 e-12$ & $3.2022 e-12$ & $2.7812 e-12$ \\
\hline & Maximum & $1.251 e-12$ & $9.0937 \mathrm{e}-12$ & $8.3118 e-12$ \\
\hline & Minimum & $-8.8742 e-13$ & $-5.3641 e-12$ & $-7.2312 e-12$ \\
\hline
\end{tabular}

commands were recalled by solver script to define constraints defining, simulate segmentation, and time step controlling.

5.1. Multistage Face Gear Impact Characteristics Analysis under the Variable Speed Condition with No Loading. To simulate the variable speed condition, input speeds were applied to cylindrical gear kinematic join; those are 100, 300, and $1000 \mathrm{r} / \mathrm{min}$, and the time functions of rotating speed were set at 5 -second intervals.

Boundary conditions and parameters were the same as above; the impact elastic displacement, impact speed, impact force, and impact potential energy are shown in Figures 17-20. 
TABle 3: Impact characteristics of third-stage face gear pair without load.

\begin{tabular}{|c|c|c|c|c|}
\hline \multirow{2}{*}{ Category } & \multirow{2}{*}{ Value } & \multicolumn{3}{|c|}{ Input speeds with no loading } \\
\hline & & $100 \mathrm{r} / \mathrm{min}$ & $300 \mathrm{r} / \mathrm{min}$ & $1000 \mathrm{r} / \mathrm{min}$ \\
\hline \multirow{3}{*}{ Elastic displacement $(\mathrm{mm})$} & Average & $-1.8876 e-8$ & $-1.15 e-8$ & $-1.1099 e-8$ \\
\hline & Maximum & $1.7158 e-5$ & $1.7158 e-5$ & $1.7159 e-5$ \\
\hline & Minimum & $-1.7158 e-5$ & $-1.7158 e-5$ & $-1.7159 e-5$ \\
\hline \multirow{3}{*}{ Impact speed $(\mathrm{mm} / \mathrm{s})$} & Average & $-7.816 e-7$ & $3.3185 e-6$ & $1.6834 e-7$ \\
\hline & Maximum & $7.4697 e-5$ & $6.7111 e-4$ & 0.007 \\
\hline & Minimum & $-7.4697 e-5$ & $-6.7114 e-4$ & -0.007 \\
\hline \multirow{3}{*}{ Impact force $(\mathrm{N})$} & Average & 489.4656 & -12606.378 & 5424.4439 \\
\hline & Maximum & $2.7706 e+5$ & $1.7801 e+6$ & $3.2413 e+6$ \\
\hline & Minimum & $-2.5713 e+5$ & $-3.2257 e+6$ & $-3.2271 e+6$ \\
\hline \multirow{3}{*}{ Potential energy (N. mm) } & Average & $-9.6468 e-12$ & $-1.4576 e-11$ & $1.6241 e-11$ \\
\hline & Maximum & $7.1451 e-12$ & $1.691 e-12$ & $3.5178 e-11$ \\
\hline & Minimum & $-2.7449 e-11$ & $-3.3082 e-11$ & $-8.336 e-13$ \\
\hline
\end{tabular}

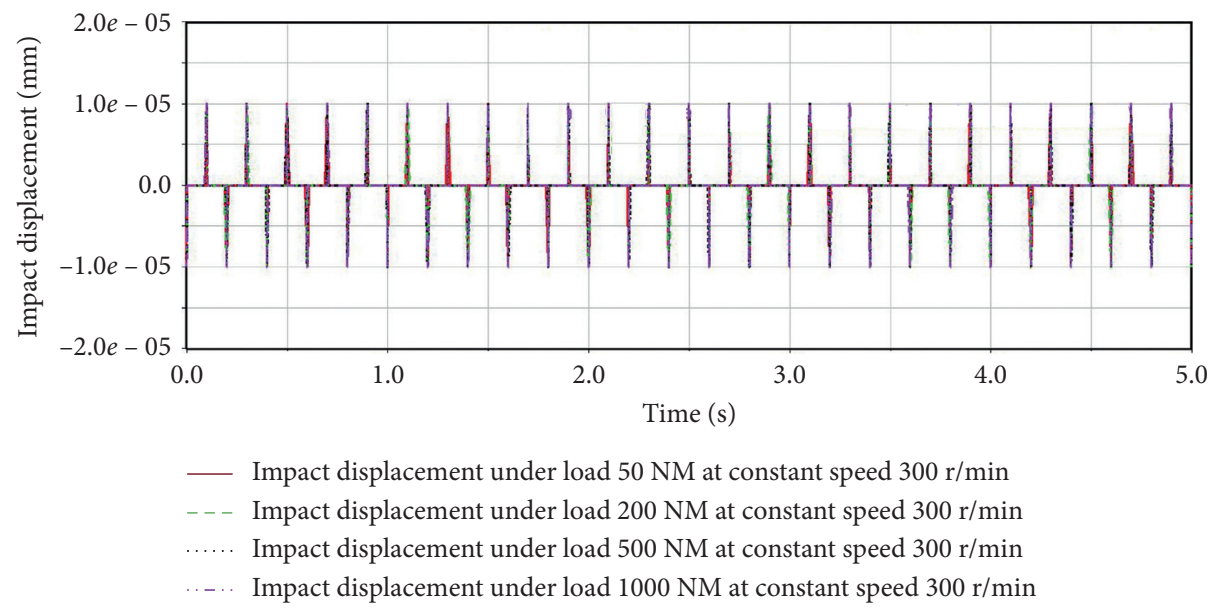

FiguRE 12: Impact elastic displacement of second-stage face gear pair under variable load.

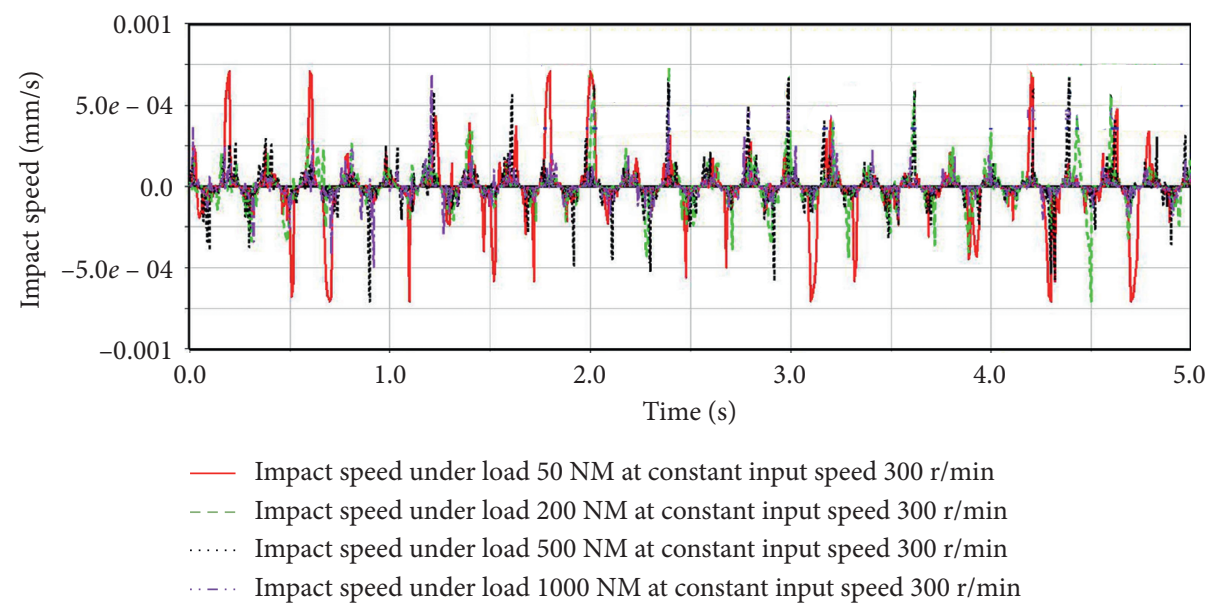

FIGURE 13: Impact speed of second-stage face gear pair under variable load.

Under variable speed with no loading, the average elastic displacement of multistage face gear is $-1.4103 e-7 \mathrm{~mm}$, the maximum is $1.7158 e-5 \mathrm{~mm}$, and the minimum is $-1.7158 e-5 \mathrm{~mm}$.

The average impact speed of the first-stage face gear is $-3.0556 e-12 \mathrm{~mm} / \mathrm{s}$, the maximum is $4.0268 e-9 \mathrm{~mm} / \mathrm{s}$, and the minimum is $-3.192 e-9 \mathrm{~mm} / \mathrm{s}$. The average impact speed of the second-stage face gear is $7.2625 e-12 \mathrm{~mm} / \mathrm{s}$, the maximum is $3.0316 e-9 \mathrm{~mm} / \mathrm{s}$, and the minimum is $-2.7292 e-9 \mathrm{~mm} / \mathrm{s}$. The average impact speed of the thirdstage face gear is $1.2286 e-12 \mathrm{~mm} / \mathrm{s}$, the maximum is $4.0452 e-9 \mathrm{~mm} / \mathrm{s}$, and the minimum is $-5.5955 e-9 \mathrm{~mm} / \mathrm{s}$. 


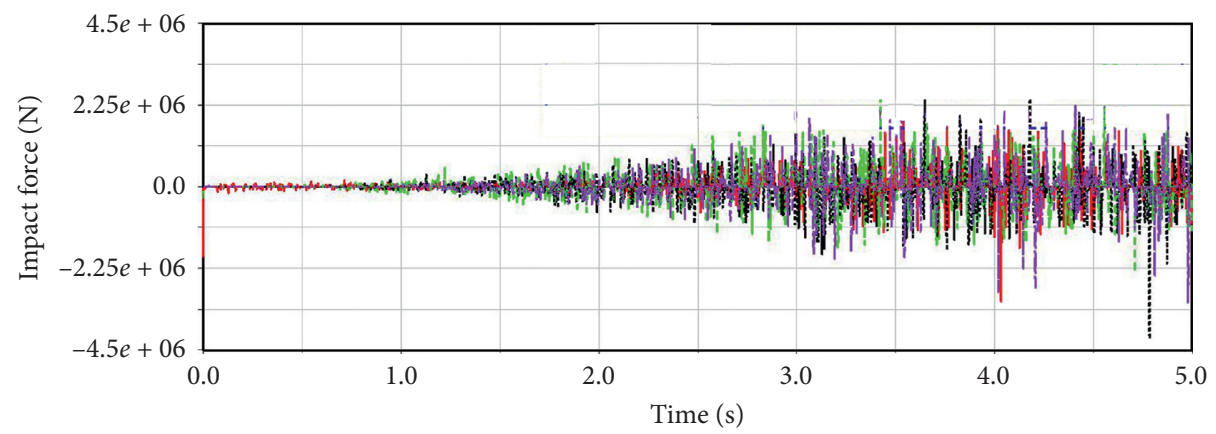

- Impact force under load $50 \mathrm{NM}$ at constant input speed $300 \mathrm{r} / \mathrm{min}$
$\ldots$ Impact force under load $200 \mathrm{NM}$ at constant input speed $300 \mathrm{r} / \mathrm{min}$
$\ldots .$. Impact force under load $500 \mathrm{NM}$ at constant input speed $300 \mathrm{r} / \mathrm{min}$
... Impact force under load $1000 \mathrm{NM}$ at constant input speed $300 \mathrm{r} / \mathrm{min}$

FIgURE 14: Impact force of second-stage face gear pair under variable load.

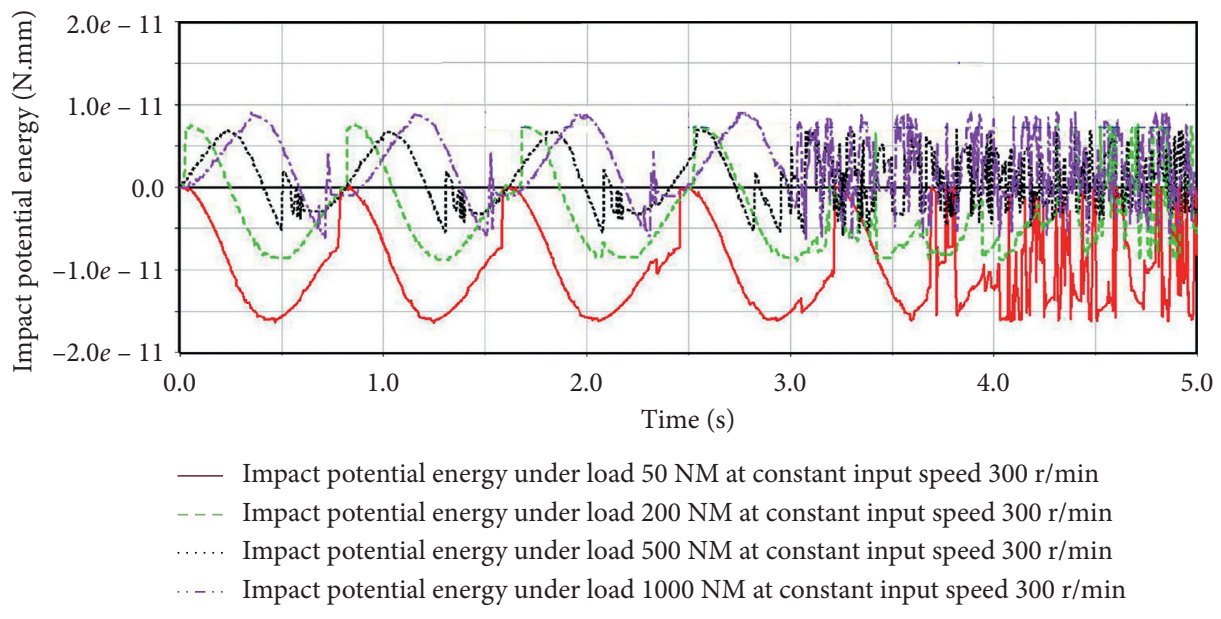

FIGURE 15: Impact potential energy of second-stage face gear pair under variable load.

TABLE 4: Impact characteristics of second-stage face gear pair with no loading.

\begin{tabular}{|c|c|c|c|c|c|}
\hline \multirow{2}{*}{ Category } & \multirow{2}{*}{ Value } & \multicolumn{4}{|c|}{ Constant input speed at $1800 \mathrm{~d}$ with variable load } \\
\hline & & $50 \mathrm{~N} \mathrm{~mm}$ & $200 \mathrm{~N} \mathrm{~mm}$ & $500 \mathrm{~N} \mathrm{~mm}$ & $1000 \mathrm{~N} \mathrm{~mm}$ \\
\hline \multirow{3}{*}{ Elastic displacement $(\mathrm{mm})$} & Average & $2.7812 e-12$ & $-6.2655 e-9$ & $-6.1767 e-9$ & $-6.0065 e-9$ \\
\hline & Maximum & $8.3118 e-12$ & $1.0025 e-5$ & $1.0026 e-5$ & $1.0026 e-5$ \\
\hline & Minimum & $-7.2312 e-12$ & $-1.0025 e-5$ & $-1.0026 e-5$ & $-1.0026 e-5$ \\
\hline \multirow{3}{*}{ Impact speed $(\mathrm{mm} / \mathrm{s})$} & Average & $-3.6226 e-6$ & $-7.5672 e-7$ & $1.9293 e-6$ & $9.9178 e-12$ \\
\hline & Maximum & $7.062 e-4$ & $5.8584 e-4$ & $6.6586 e-4$ & $6.774 e-4$ \\
\hline & Minimum & $-7.062 e-4$ & $-7.062 e-4$ & $-7.062 e-4$ & $-4.9694 e-4$ \\
\hline \multirow{3}{*}{ Impact force $(\mathrm{N})$} & Average & -7331.2135 & -9540.3287 & 12724.0843 & -9526.0254 \\
\hline & Maximum & $3.1548 e+6$ & $2.3528 e+6$ & $4.1946 e+6$ & $3.2087 e+6$ \\
\hline & Minimum & $-1.8003 e+6$ & $-2.4418 e+6$ & $-2.5312 e+6$ & $-2.2345 e+6$ \\
\hline \multirow{3}{*}{ Potential energy (N. mm) } & Average & $-9.8052 e-12$ & $-2.8836 e-12$ & $9.3807 e-13$ & $2.6048 e-12$ \\
\hline & Maximum & $2.8218 e-13$ & $7.6622 e-12$ & $6.9592 e-12$ & $9.04 e-12$ \\
\hline & Minimum & $-1.6372 e-11$ & $-8.8735 e-12$ & $-5.7774 e-12$ & $-6.4243 e-12$ \\
\hline
\end{tabular}

The average impact force of the first-stage face gear is $-3522.2826 \mathrm{~N}$, the maximum is $4.0564 e+6 \mathrm{~N}$, and the minimum is $-3.2795 e+6 \mathrm{~N}$. The average impact force of the second-stage face gear is $-2226.9693 \mathrm{~N}$, the maximum is $4.112 e+6 \mathrm{~N}$, and the minimum is $-3.2088 e+6 \mathrm{~N}$. The average impact force of the third-stage face gear is
$1438.7766 \mathrm{~N}$, the maximum is $2.6672 e+6 \mathrm{~N}$, and the minimum is $-2.7074 e+6 \mathrm{~N}$.

The average impact potential energy of the first-stage face gear is $4.9842 e-11 \mathrm{~N} \mathrm{~mm}$, the maximum is $1.104 e-10 \mathrm{~N}$ $\mathrm{mm}$, and the minimum is $-1.0296 e-11 \mathrm{~N} \mathrm{~mm}$. The average impact potential energy of the second-stage face gear is 


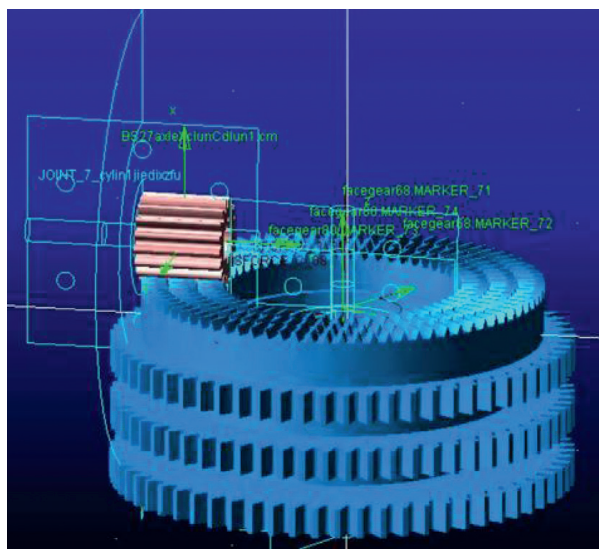

FIgURE 16: Dynamic model analysis of multistage face gear in ADAMS.

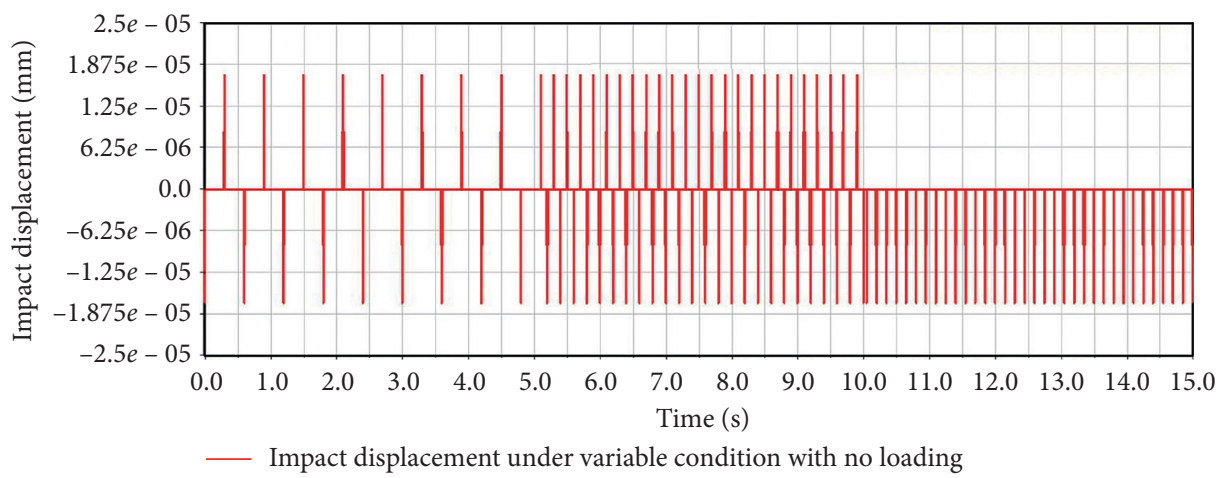

FIGURE 17: Impact elastic displacement of multistage face gear pair under variable speed with no loading.

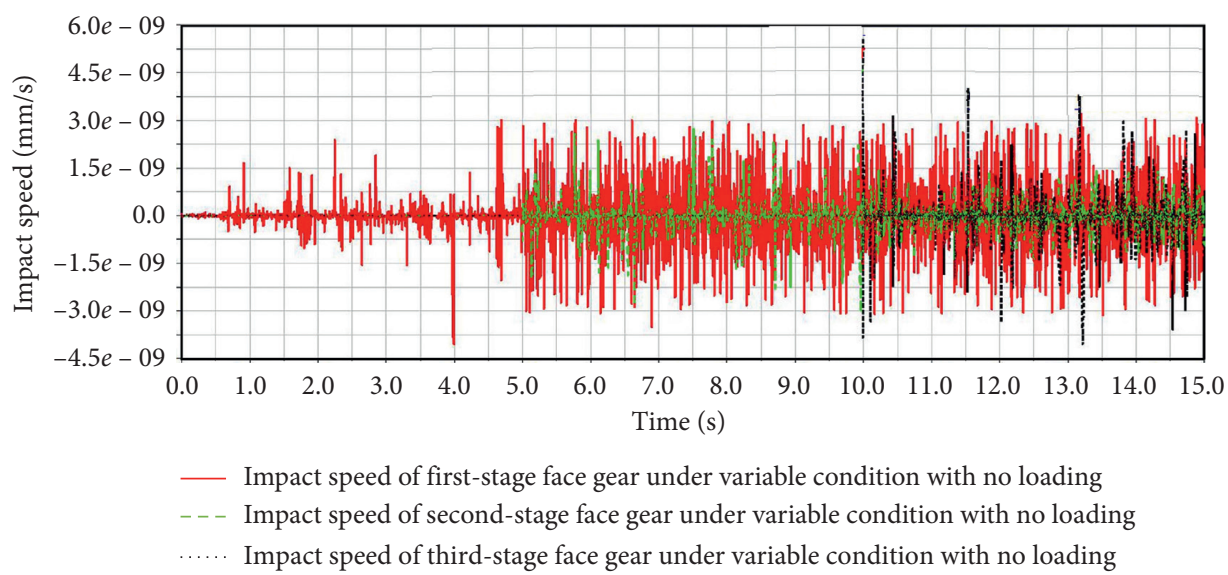

FIGURE 18: Impact speed of multistage face gears pair under variable speed with no loading.

$4.2229 e-11 \mathrm{~N} \mathrm{~mm}$, the maximum is $1.2835 e-10 \mathrm{~N} \mathrm{~mm}$, and the minimum is $-2.7808 e-13 \mathrm{~N} \mathrm{~mm}$. The average impact potential energy of the third-stage face gear is $8.6744 e-12 \mathrm{~N}$ $\mathrm{mm}$, the maximum is $7.6 e-11 \mathrm{~N} \mathrm{~mm}$, and the minimum is $-2.2555 e-11 \mathrm{~N} \mathrm{~mm}$.

Under variable speed with no loading, there were no significant changes in impact elastic displacement, impact speed, and impact force of all stages face gears because the material, surface processing technology, and structural clearance controlling were roughly the same; however, the impact elastic potential energy gradually decreased. As the input speed increased, the elastic displacement period of multistage face gear system decreased, but the fluctuation amplitude increased. The impact speed amplitude also increased. Averages of impact force amplitudes of all stages gears were basically the same, whereas the impact forces suddenly increased during each shifting process as the input speed. When the transmission switched to the second stage, the input speed increased, and the existing meshing rotation inertia of first-stage face gear also increased, the time 


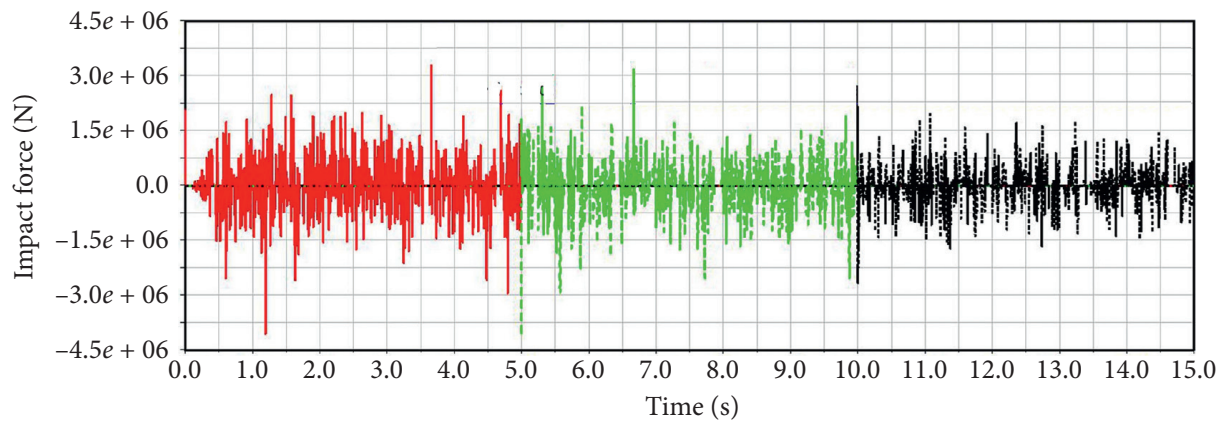

_ Impact force of first-stage face gear under variable condition with no loading

- - - Impact force of second-stage face gear under variable condition with no loading

..... Impact force of third-stage face gear under variable condition with no loading

FIGURE 19: Impact force of multistage face gears pair under variable speed with no loading.

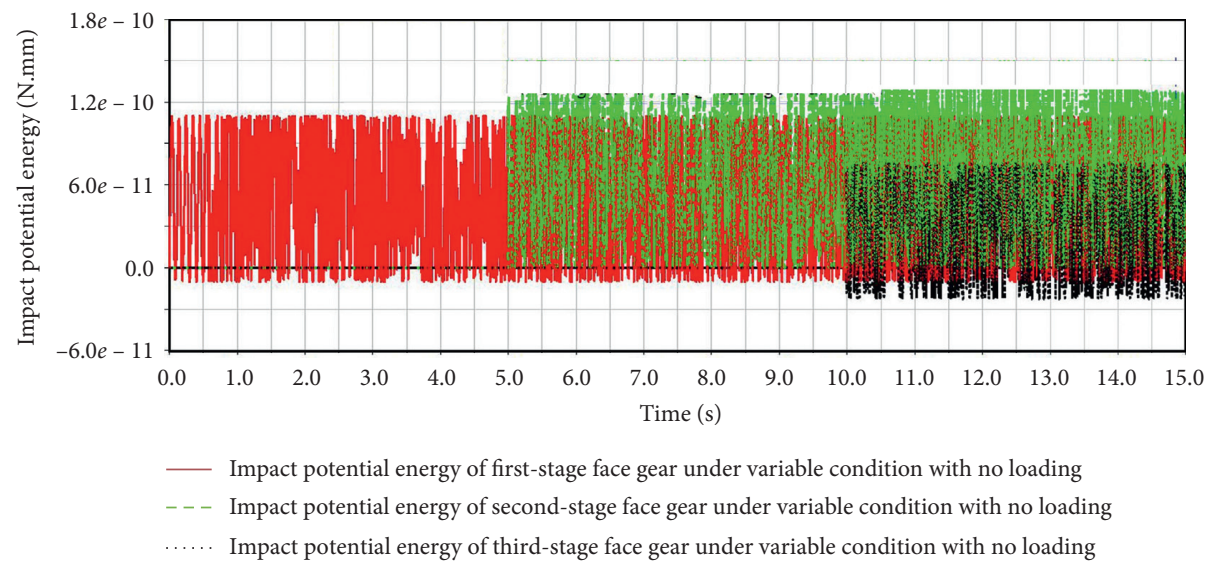

FIgURE 20: Impact potential energy of multistage face gears pair under variable speed with no loading.

between teeth meshing-out decreased, the relative speed increased, and the average impact elastic potential energy increased.

\subsection{Analysis of Multistage Face Gear Impact Characteristics} under Constant Speed and Variable Load. To simulate the variable load, the input load torques were applied to various stage face gears kinematic joins; those are 50, 200, 500, and $1000 \mathrm{~N} \mathrm{~mm}$, and the time functions of torque were set at 5second intervals.

The input speed was set to $1800 \mathrm{~d}$; all other boundary conditions and parameters remained the same. Thus, the impact elastic displacement, impact speed, impact force, and impact potential energy are presented in Figures 21-24.

Under variable load at constant speed, the average elastic displacement of multistage face gear is $-4.0544 e-9 \mathrm{~mm}$, the maximum is $1.7158 e-5 \mathrm{~mm}$, and the minimum is $-1.7158 e-5 \mathrm{~mm}$.

The average impact speed of the first-stage face gear is $-2.0046 e-12 \mathrm{~mm} / \mathrm{s}$, the maximum is $1.4651 e-9 \mathrm{~mm} / \mathrm{s}$, and the minimum is $-2.6721 e-9 \mathrm{~mm} / \mathrm{s}$. The average impact speed of the second-stage face gear is $-7.4868 e-12 \mathrm{~mm} / \mathrm{s}$, the maximum is $3.463 e-9 \mathrm{~mm} / \mathrm{s}$, and the minimum is $-7.0923 e-9 \mathrm{~mm} / \mathrm{s}$. The average impact speed of the thirdstage face gear is $-7.8208 e-12 \mathrm{~mm} / \mathrm{s}$, the maximum is $4.3068 e-9 \mathrm{~mm} / \mathrm{s}$, and the minimum is $-7.3688 e-9 \mathrm{~mm} / \mathrm{s}$.

The average impact force of the first-stage face gear is $8452.1594 \mathrm{~N}$, the maximum is $3.6891 e+6 \mathrm{~N}$, and the minimum is $-1.9428 e+6 \mathrm{~N}$. The average impact force of the second-stage face gear is $199.8161 \mathrm{~N}$, the maximum is $2.063 e+6 \mathrm{~N}$, and the minimum is $-2.671 e+6 \mathrm{~N}$. The average impact force of the third-stage face gear is $3543.5363 \mathrm{~N}$, the maximum is $3.048 e+6 \mathrm{~N}$, and the minimum is $-2.8631 e+6 \mathrm{~N}$.

The average impact potential energy of the first-stage face gear is $4.9998 e-11 \mathrm{~N} \mathrm{~mm}$, the maximum is $1.1046 e-10 \mathrm{~N} \mathrm{~mm}$, and the minimum is $-1.0258 e-11 \mathrm{~N}$ $\mathrm{mm}$. The average impact potential energy of the secondstage face gear is $6.2415 e-11 \mathrm{~N} \mathrm{~mm}$, the maximum is $1.291 e-10 \mathrm{~N} \mathrm{~mm}$, and the minimum is $-4.8665 e-13 \mathrm{~N}$ $\mathrm{mm}$. The average impact potential energy of the third-stage face gear is $2.6771 e-11 \mathrm{~N} \mathrm{~mm}$, the maximum is $7.6 e-11 \mathrm{~N}$ $\mathrm{mm}$, and the minimum is $-2.2602 e-11 \mathrm{~N} \mathrm{~mm}$.

Under constant speed and variable load, the impact elastic displacements did not significant change for every 


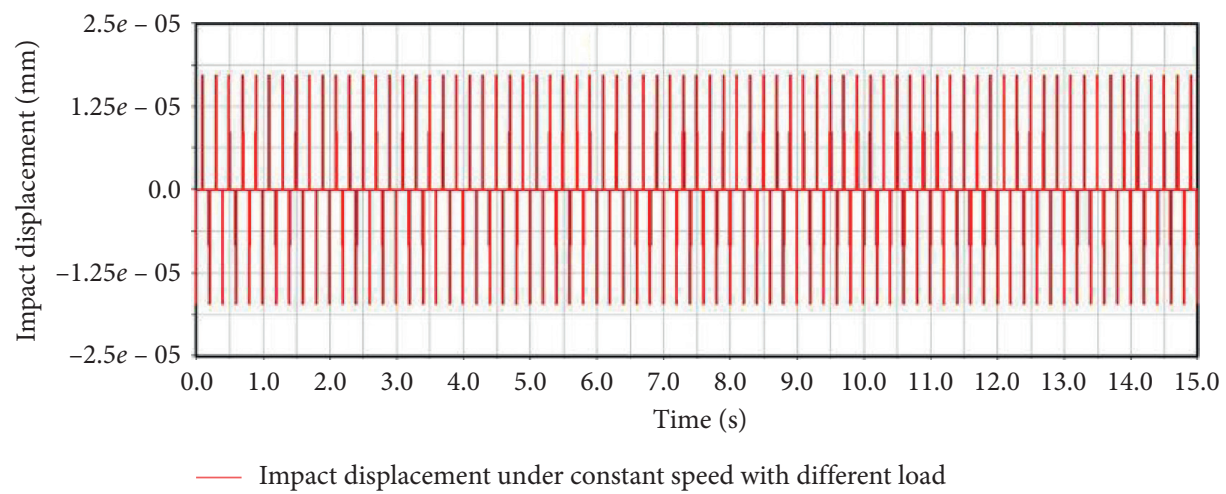

FIGURE 21: Impact elastic displacement of multistage face gear pair under constant speed and variable load.

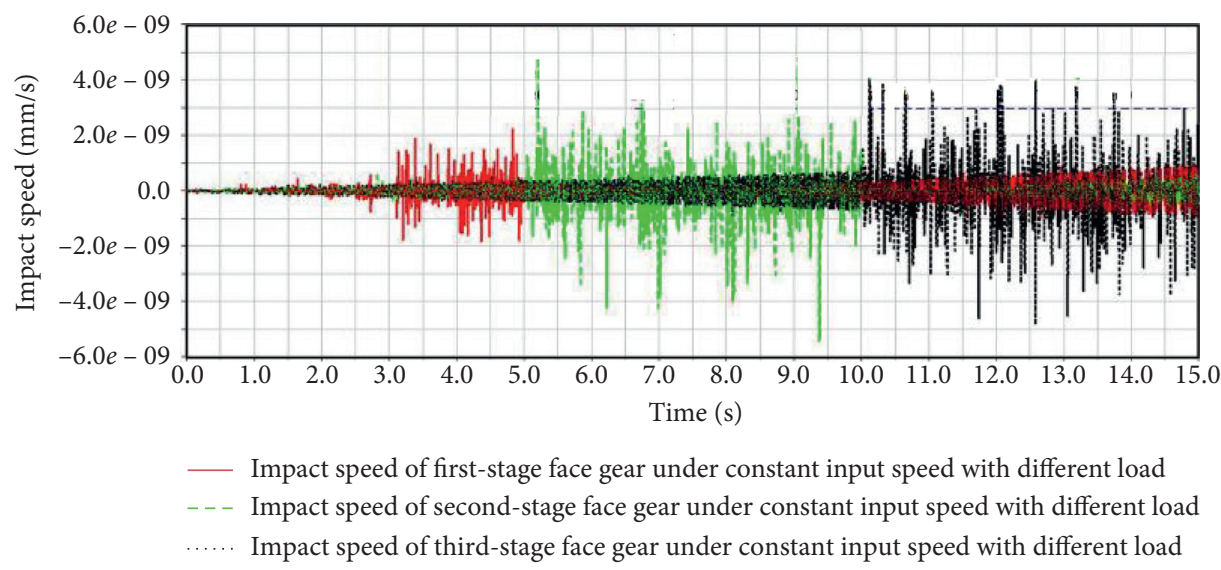

FIGURE 22: Impact speed of multistage face gears pair under constant speed and variable load.

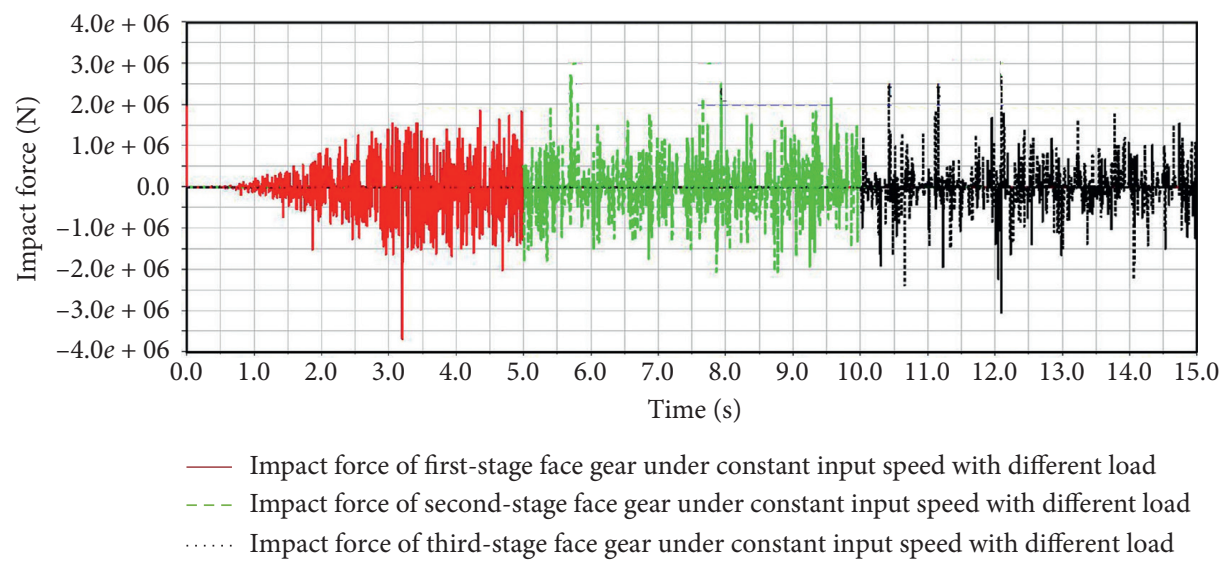

Figure 23: Impact force of multistage face gears pair under constant speed and variable load.

stage. As the load increased, the impact speed amplitude increased, but the periods shortened. The impact force amplitude decreased as the gear stage increased and also decreased as the load increased. Under the low transmission ratio stages or load conditions, all impact elastic potential energies exhibit significant periodical fluctuations. As the stages increased, the elastic potential energy amplitudes firstly increased and then decreased, which in the secondstage face gear also decreased with the load increased.

Thus, the transmission ratio should be reasonably adjusted to allow for speed and load changes, minimize differences in crown quantities among stages of face gears, and an appropriate gears shift mechanism should be adopted to achieve smooth gear shifting. 


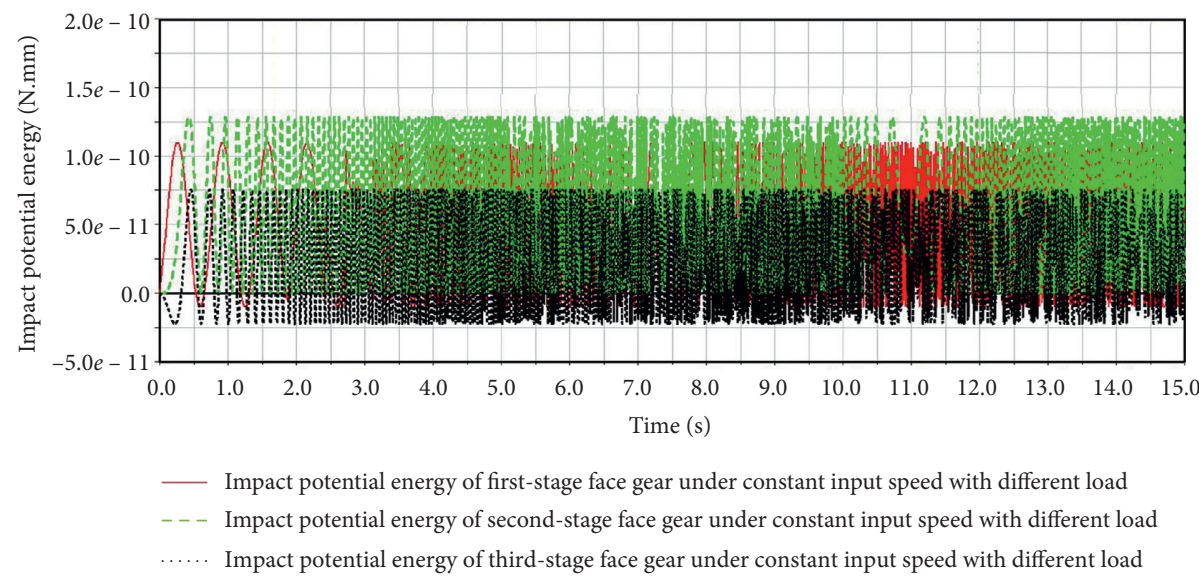

FIGURE 24: Impact potential energy of multistage face gears pair under constant speed and variable load.

\section{Conclusions}

A gear impact characteristic model was established in this paper. A contact impact relationship was defined for face gear; then impact force, impact speed, and contact meshing force were analyzed, and the main characteristic parameters in the impact model were extracted.

Taking the single-stage face gear pair as research object, the impact characteristics were comparatively studied under four operating conditions: variable/no load and constant/ variable speed. The transient characteristics of crown gears with contact deformation and frequent variable speed impacts were studied under various conditions. Then, the impact characteristics of multistage face gears pairs under four conditions were extensively studied.

The results verify the characteristics of multistage face gears pair, including fluctuation of the meshing force and impact force, which can adapt to multiple loads as well as continuous acceleration/deceleration process. This paper provides a method for avoiding dangerous points by assessing the contact strength and bending strength of teeth surface. Moreover, the approach can be beneficial to evaluate the structural parameters rationality of multistage crown face gears and comprehensively investigate the applicability and boundary conditions for variable speed transmission system.

\section{Data Availability}

No data sets were used to support this study.

\section{Conflicts of Interest}

The authors declare no conflicts of interest with respect to the research, authorship, and/or publication of this article.

\section{Authors' Contributions}

M. X. and Z. P. conceived and designed the article; L. N. performed the gear impact model; Z. H. analyzed transient characteristics of the crown gear under contact deformation or frequent shifting impact; W. Y. analyzed and determined the meshing force and impact force fluctuation characteristics; and C. X. wrote the paper.

\section{Acknowledgments}

The authors would like to thank Miss Tian Xu for English editing. The authors would like to thank MogoEdit Company for modifying the manuscript with native language. This work was supported by the National Key Research and Development Plan of China (Grant no. 2017YFB1301400) and the Guangdong Provincial Enterprises Key Laboratory Foundation about Mid-High-End Industrial Robot Technology (Grant no. 2018B030323027).

\section{References}

[1] F. Concli, "Low-loss gears precision planetary gearboxes: reduction of the load dependent power losses and efficiency estimation through a hybrid analytical-numerical optimization tool," Forschung im Ingenieurwesen, vol. 81, no. 4, pp. 395-407, 2017.

[2] X. Chen, Q. Hu, Z. Xu, and C. Zhu, "Numerical modeling and dynamic characteristics study of coupling vibration of multistage face gearsplanetary transmission," Mechanical Sciences, vol. 10, no. 2, pp. 475-495, 2019.

[3] J. M. Yang and P. Yang, "Random vibration and dynamic analysis of a planetary gear train in a wind turbine," Shock and Vibration, vol. 2016, Article ID 6292953, 10 pages, 2016.

[4] W. Wang, H. Liu, C. Zhu, and Z. Sun, "Evaluation of contact fatigue life of a wind turbine carburized gear considering gradients of mechanical properties," International Journal of Damage Mechanics, vol. 28, no. 8, pp. 1170-1190, 2019.

[5] F. Bogard, P. Lestriez, and Y. Q. Guo, "Numerical modeling of fatigue damage and fissure propagation under cyclic loadings," International Journal of Damage Mechanics, vol. 17, no. 2, pp. 173-187, 2008.

[6] J. X. Zhou, W. L. Sun, and L. Yuan, "Nonlinear vibroimpact characteristics of a planetary gear transmission system," Shock and Vibration, vol. 2016, Article ID 4304525, 11 pages, 2016.

[7] Z. Wang, W. Pu, T. He, J. Wang, and W. Cao, "Numerical simulation of transient mixed elastohydrodynamic lubrication for spiral bevel gears," Tribology International, vol. 139, pp. 67-77, 2019. 
[8] J. Tan, C. Zhu, C. Song, X. Xu, and Z. Wang, "Investigation of dynamic characteristics of planetary gear stage in wind turbine considering voltage dip," Journal of Mechanical Science and Technology, vol. 33, no. 9, pp. 4139-4154, 2019.

[9] D. Xiang, Y. H. Shen, and Y. Z. Wei, "A contact force model considering meshing and collision states for dynamic analysis in helical gear system," Chinese Journal of Mechanical Engineering, vol. 32, no. 1, 2019.

[10] Y. Gui, Q. K. Han, Z. Li, and F. L. Chu, "Detection and localization of tooth breakage fault on wind turbine planetary gear system considering gear manufacturing errors," Shock and Vibration, vol. 2014, Article ID 692347, 13 pages, 2014.

[11] Y. Mu, Z. Fang, and W. Li, "Impact analysis and vibration reduction design of spiral bevel gears," Proceedings of the Institution of Mechanical Engineers, Part K: Journal of MultiBody Dynamics, vol. 233, no. 3, pp. 668-676, 2019.

[12] S. Kimme, R. Bauer, W. G. Drossel, and M. Putz, "Simulation of error-prone continuous generating production processes of helical gears and the influence on the vibration excitation in gear mesh," in Proceedings of the 10th Cirp Conference on Intelligent Computation in Manufacturing Engineering-Cirp Icme '16, vol. 62, pp. 256-261, Ischia, Italy, July 2016.

[13] Y.-C. Chung and Y.-R. Wu, "Dynamic modeling of a gear transmission system containing damping particles using coupled multi-body dynamics and discrete element method," Nonlinear Dynamics, vol. 98, no. 1, pp. 129-149, 2019.

[14] P. Ziegler and P. Eberhard, "Investigation of gears using an elastic multibody model with contact," Computational Methods in Applied Sciences, vol. 23, pp. 309-327, 2011.

[15] J. Y. Tang, Q. B. Wang, L. J. Wu, and S. Y. Chen, "Bifurcation analysis of impact model in gear transmission system," $A p$ plied Mechanics and Materials, vol. 86, pp. 479-482, 2011.

[16] G. Feng, Z. Xie, and M. Zhou, "Geometric design and analysis of face-gear drive with involute helical pinion," Mechanism and Machine Theory, vol. 134, pp. 169-196, 2019.

[17] A. Suzuki, I. Tarutani, and T. Aoyama, "Design of high-reduction hypoid gears meshing in plane of action," Journal of Advanced Mechanical Design, Systems, and Manufacturing, vol. 11, no. 6, Article ID JAMDSM0068, 2017.

[18] S. Li, "Effect of addendum on contact strength, bending strength and basic performance parameters of a pair of spur gears," Mechanism and Machine Theory, vol. 43, no. 12, pp. 1557-1584, 2008.

[19] Q. Hu, X. Chen, Z. Xu, Q. Mai, and C. Zhu, "Study on kinematic characteristics of planetary multistage face gears transmission," Proceedings of the Institution of Mechanical Engineers, Part D: Journal of Automobile Engineering, vol. 234, no. 2-3, Article ID 095440701985590, 2020.

[20] X. Chen, Q. Hu, Z. Xu, Y. Ding, Q. Mai, and C. Zhu, "Simulation analysis on quasistatic characteristics of multistage face gears with double crown surface," Computer Modeling in Engineering \& Sciences, vol. 118, no. 2, pp. 447-470, 2019.

[21] Z. M. Li, H. Wu, and R. P. Zhu, "Influence predictions of geometric parameters on face gear strength," Advances in Mechanical Engineering, vol. 7, no. 2, 2015.

[22] J.-Y. Tang and Y.-P. Liu, "Loaded multi-tooth contact analysis and calculation for contact stress of face-gear drive with spur involute pinion," Journal of Central South University, vol. 20, no. 2, pp. 354-362, 2013.

[23] I. Gonzalez-Perez, J. L. Iserte, and A. Fuentes, "Implementation of Hertz theory and validation of a finite element model for stress analysis of gear drives with localized bearing contact," Mechanism and Machine Theory, vol. 46, no. 6, pp. 765-783, 2011.

[24] C. K. Lee, "The mathematical model and a case study of the cosine face gear drive that has a predesigned fourth order function of transmission errors and a localized bearing contact," Advances in Mechanical Engineering, vol. 11, no. 2, 2019.

[25] C. He and C. Lin, "Analysis of loaded characteristics of helical curve face gear," Mechanism and Machine Theory, vol. 115, pp. 267-282, 2017.

[26] L. Liu and J. Z. Zhang, "Meshing characteristics of a sphereface gear pair with variable shaft angle," Advances in Mechanical Engineering, vol. 11, no. 6, 2019.

[27] S. Wei, J. Zhao, Q. Han, and F. Chu, "Dynamic response analysis on torsional vibrations of wind turbine geared transmission system with uncertainty," Renewable Energy, vol. 78, pp. 60-67, 2015.

[28] C. M. Firrone and S. Zucca, "Passive control of vibration of thin-walled gears: advanced modelling of ring dampers," Nonlinear Dynamics, vol. 76, no. 1, pp. 263-280, 2014.

[29] R. Wang, K. Shi, J. Q. Xia, and C. Geng, "The research of noncircular bevel gears' undercut condition," in Proceedings of the Asme International Mechanical Engineering Congress and Exposition, vol. 11, Houston, TX, USA, November 2015.

[30] M. H. Xiao, Y. W. Wang, F. Zou, H. Zhang, and X. Li, "Dynamic simulation research of hydro-mechanical CVT," IETE Journal of Research, vol. 4, pp. 1-12, 2019.

[31] J. I. Pedrero, M. Pleguezuelos, M. Artés, and J. A. Antona, "Load distribution model along the line of contact for involute external gears," Mechanism and Machine Theory, vol. 45, no. 5, pp. 780-794, 2010.

[32] X. W. Tangpong, J. A. Wickert, and A. Akay, "Finite element model for hysteretic friction damping of traveling wave vibration in axisymmetric structures," Journal of Vibration and Acoustics, vol. 130, no. 1, 2008.

[33] K. Salagianni, P. Nikolakopoulos, and S. Theodossiades, "Dynamic and tribological study of a planetary gearbox with local nonlinearities," Proceedings of the Institution of $\mathrm{Me}$ chanical Engineers, Part K: Journal of Multi-Body Dynamics, vol. 231, no. 3, pp. 504-518, 2017.

[34] K. Vuckovic, I. Galic, Z. Bozic, and S. Glodež, "Effect of friction in a single-tooth fatigue test," International Journal of Fatigue, vol. 114, pp. 148-158, 2018.

[35] F. G. O'neill, K. Summerbell, and A. Ivanović, "The contact drag of towed demersal fishing gear components," Journal of Marine Systems, vol. 177, pp. 39-52, 2018.

[36] M. Octrue, D. Ghribi, and P. Sainsot, "A contribution to study the tooth flank fracture (TFF) in cylindrical gears," in Proceedings of the 7th International Conference on Fatigue Design, vol. 213, pp. 215-226, Senlis, France, November 2017. 